\title{
Nuclear Fuel Cycle and Supply Chain (NFCSC) Technical Monthly September FY-19
}

The INL is a U.S. Department of Energy National Laboratory operated by Battelle Energy Alliance 


\section{DISCLAIMER}

This information was prepared as an account of work sponsored by an agency of the U.S. Government. Neither the U.S. Government nor any agency thereof, nor any of their employees, makes any warranty, expressed or implied, or assumes any legal liability or responsibility for the accuracy, completeness, or usefulness, of any information, apparatus, product, or process disclosed, or represents that its use would not infringe privately owned rights. References herein to any specific commercial product, process, or service by trade name, trade mark, manufacturer, or otherwise, does not necessarily constitute or imply its endorsement, recommendation, or favoring by the U.S. Government or any agency thereof. The views and opinions of authors expressed herein do not necessarily state or reflect those of the U.S. Government or any agency thereof. 


\title{
Nuclear Fuel Cycle and Supply Chain (NFCSC) Technical Monthly September FY-19
}

Idaho National Laboratory Idaho Falls, Idaho 83415

\author{
http://www.inl.gov
}

Prepared for the

U.S. Department of Energy

Office of Nuclear Energy

Under DOE Idaho Operations Office

Contract DE-AC07-05ID14517 



\section{CONTENTS}

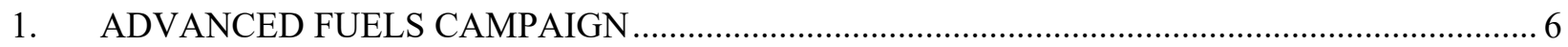

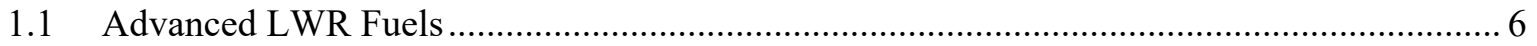

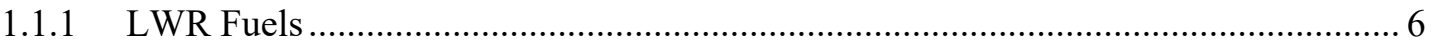

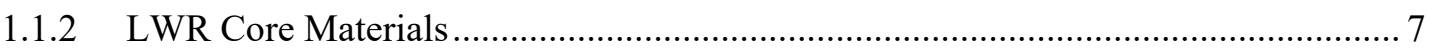

1.1.3 LWR Irradiation Testing \& PIE Techniques ...................................................... 7

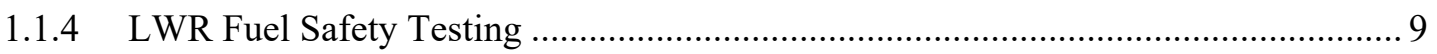

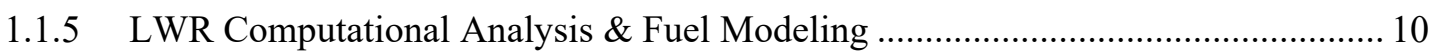

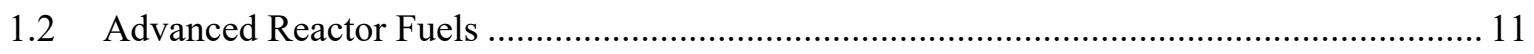

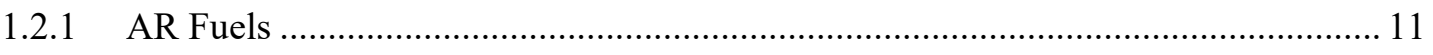

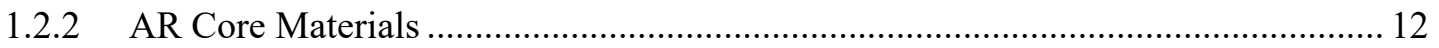

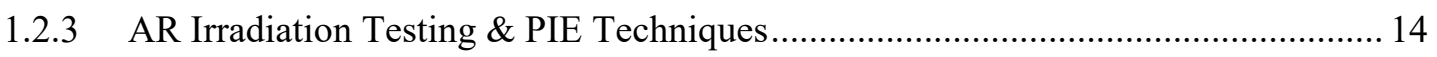

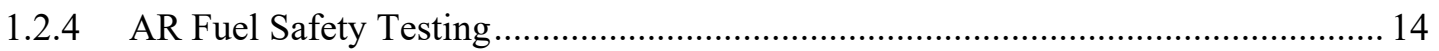

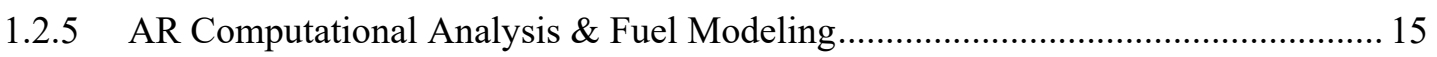

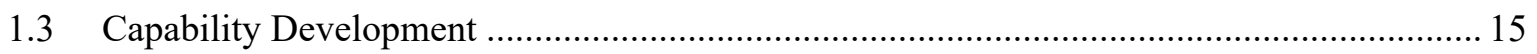

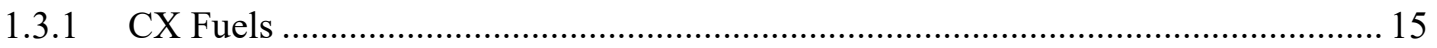

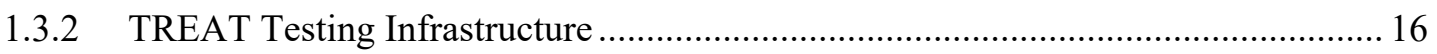

2. MATERIAL RECOVERY AND WASTE FORMS DEVELOPMENT …..................................... 17

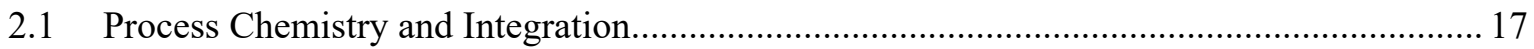

2.2 Waste Form Development and Performance .................................................................... 19

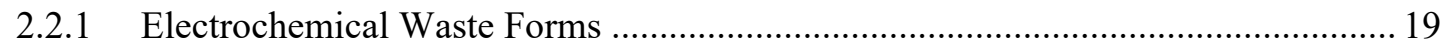

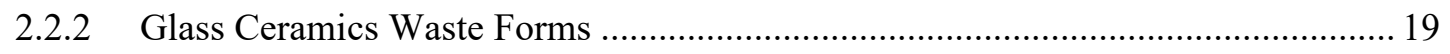

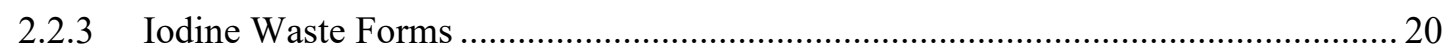

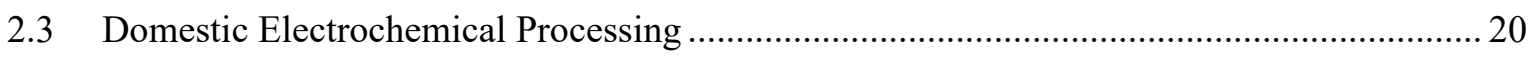

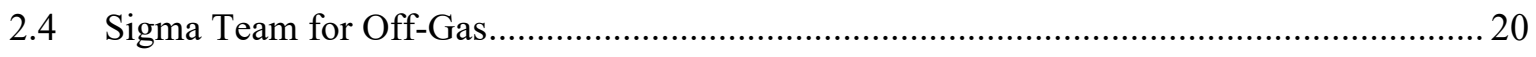

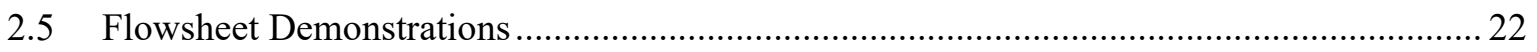

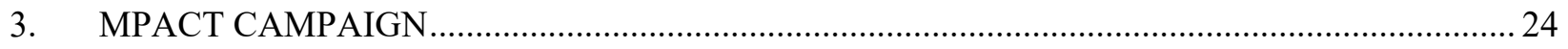

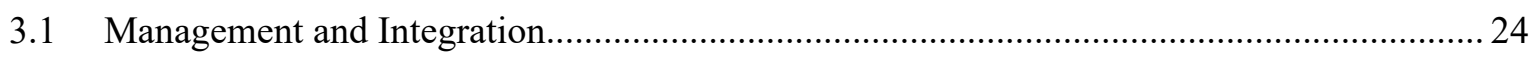

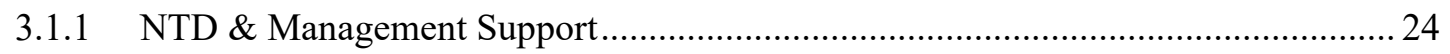

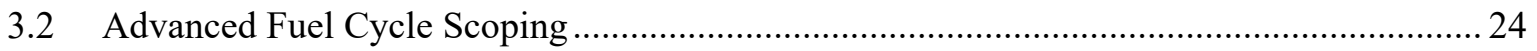

3.2.1 Advanced Process Modeling and Simulation Process Tests ..................................... 24

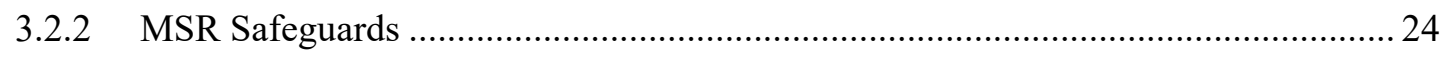

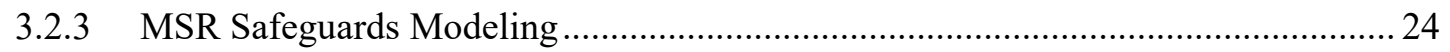

3.2.4 Advanced Fuel Cycle Scoping Review Panel ......................................................... 24

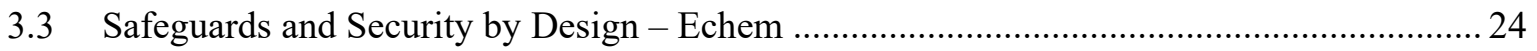

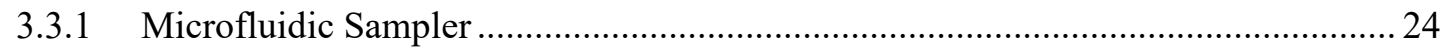

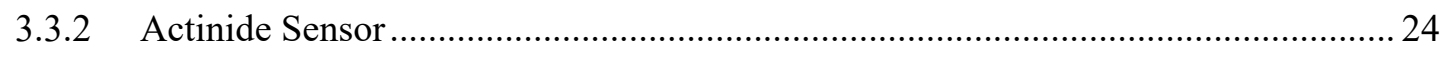

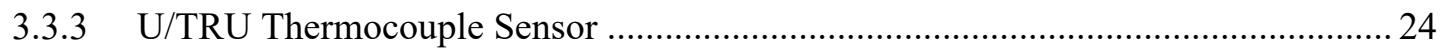


3.3.4 Bubbler for Measuring Density and Depth of Molten Salt .................................... 25

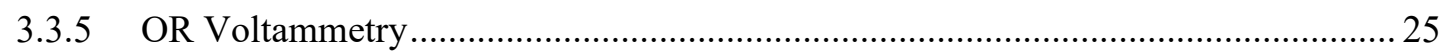

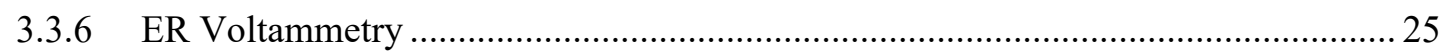

3.4 Modeling Advanced Integration and Milestone 2020:.................................................... 25

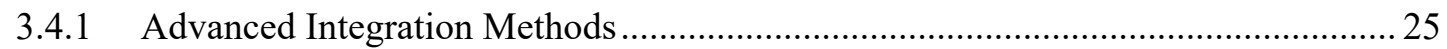

3.4.2 Modeling and Simulation for Analysis of Safeguards Performance......................... 25

3.5 Exploratory Research / Field Tests ............................................................................ 25

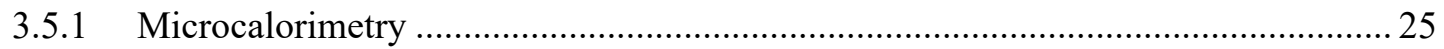

4. SYSTEMS ANALYSIS AND INTEGRATION (SA\&I) CAMPAIGN ....................................... 26

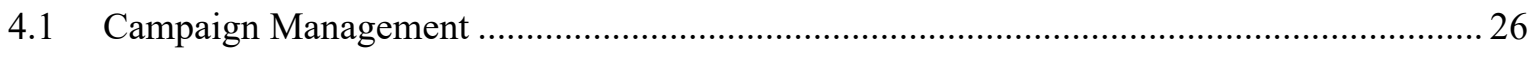

4.2 EQUILIBRIUM SYSTEM PERFORMANCE (ESP)..................................................... 26

4.2.1 Performance of Advanced Nuclear Energy Systems ...............................................26

4.2.2 Economic Analysis Capabilities and Assessments ................................................ 26

4.2.3 Daily Market Studies of Advanced Nuclear Energy Systems.................................. 27

4.2.4 Enhancements to the Cost Basis Report (CBR) Tool .............................................. 27

4.2.5 Analysis of NES to Augment Information in Fuel Cycle Catalog ............................ 27

4.2.6 Maintain/Update Campaign Analysis Tools ......................................................... 27

4.2.7 Campaign Special Sessions at International Topical Conference ............................. 27

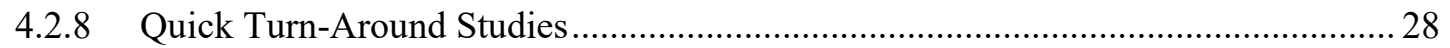

4.2.9 Beyond Levelized Cost of Electricity ................................................................ 28

4.3 DEVELOPMENT, DEPLOYMENT AND IMPLEMENTATION ISSUES (DDII)............. 28

4.3.1 Technology Development Roadmap for a Continuous Recycle System Using Fast

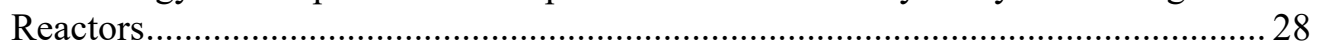

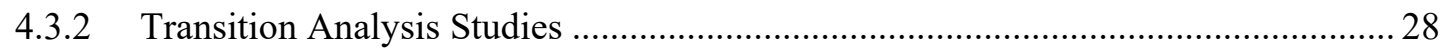

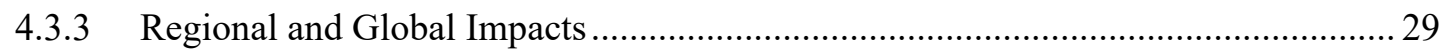

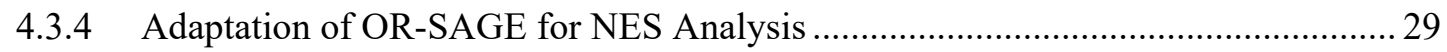

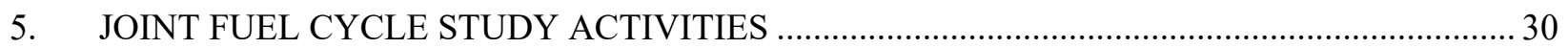

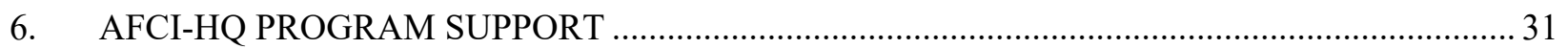

6.1 Innovations in Nuclear Technology R\&D Awards ............................................................ 32

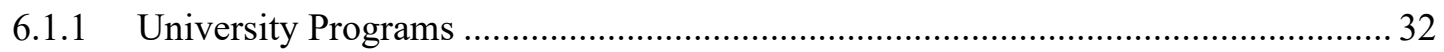




\section{FIGURES}

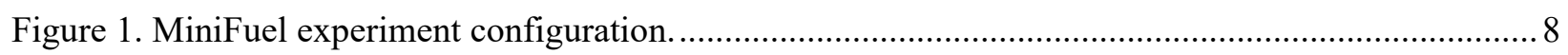

Figure 2. LOCA test train with a reduced length cladding segment (4") showed similar burst

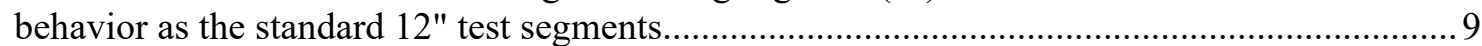

Figure 3. Comparison of peak cladding temperature among sensitivity cases. ...................................... 11

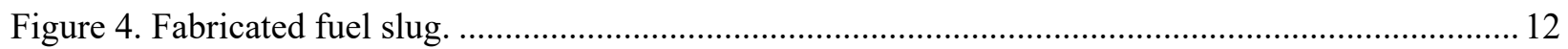

Figure 5. Longer actuator during installation on the rolling mill........................................................ 13

Figure 6. Laser Flash Analyzer (left) and Thermal Conductivity Microscope (right) installed in

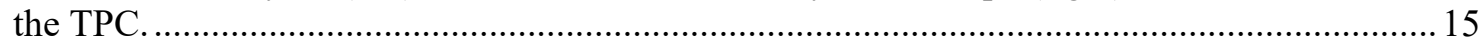

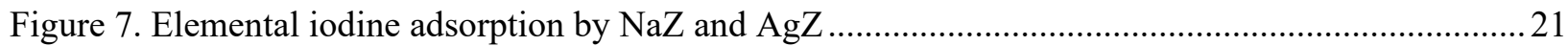




\section{Nuclear Fuel Cycle and Supply Chain (NFCSC) Technical Monthly September FY-19}

\section{ADVANCED FUELS CAMPAIGN}

\subsection{Advanced LWR Fuels}

\subsubsection{LWR Fuels}

[LANL] The Level 2 milestone titled, "Report on waterproofing of UN studies," was completed. The report examines two concepts being considered for the waterproofing of UN, which include (1) liquidphase sintering with a corrosion-resistant metal (cermet) and (2) co-sintering with a corrosion-resistant ceramic. Liquid-phase sintering of UN with silicon and chromium metals was attempted as well as a composite with silicon carbide. Liquid-phase sintering studies of UN-Cr composites showed significant mass loss that resulted from chromium volatilization at elevated temperature. Composites with Si showed extensive reaction with the UN to form uranium silicides, as identified using XRD. Reactive sintering of $\mathrm{SiC}$ from $\mathrm{Si}$ and graphite was found to be successful, but the resultant pellet contained small quantities of remaining Si. Two-step sintering of $\mathrm{UN}-\mathrm{SiC}$ pellets showed a reaction with $\mathrm{UN}$, resulting in sample deterioration and chemical interaction with the $\mathrm{W}$ metal crucible. Further studies of the thermodynamic stability of UN with SiC are warranted given the interest for ATF concepts. From the results of this Level 2 milestone and those of the preceding Level 3 milestone, a new evaluation of candidate materials was highlighted. As waterproofing candidates are identified, future work will continue to holistically evaluate concepts to safely incorporate UN in LWR environments. (A. Shivprasad, A. Telles, J. White)

[LANL] Initial measurements of spatial distribution of $\mathrm{O} / \mathrm{M}$ ratios in flash sintered $\mathrm{UO} 2$ pellets were performed on flight path 5 at LANSCE. These ongoing measurements aim to combine the techniques of Energy-Resolved Neutron Imaging (ERNI) and Computed Tomography (CT) to extract 3D spatial mappings of Uranium and Oxygen isotope distributions within dUO2 pellets that were flashed under Direct Current (DC) and under Alternating Current (AC). It is expected that an $\mathrm{O} / \mathrm{M}$ gradient will develop in the UO2 pellets flashed under DC and this will influence the sintering kinetics and characteristics. Mapping this behavior for AC versus DC flash of UO2 will give better insight and help identify the optimal flash conditions. (Alex Long, E. Kardoulaki)

[ORNL] The Level 3 milestone (M3FT-19OR020201077) titled, "Progress on synthesis of novel fuel microstructures containing low content inert matrix materials," due on September 13th was successfully completed. A technical report, ORNL/LTR-2019/1294, titled "Progress on synthesis of low content inert matrix fuel pellets," summarizes the progress made at ORNL on fabricating representative low volume content inert matrix fuel microstructures for drop-in fuels for the existing reactor fleet. The aim of the work was pressing pellets with little to no sintering aid and infiltrating the pellets using chemical vapor infiltration to create a protective barrier, to increase structural integrity of the fuel, and to provide a seal on the pressed pellet. Two forms of surrogate fuel material (porous $\mathrm{CeO} 2$ and dense $\mathrm{ZrO} 2$ ) and their outcome from hot pressing were studied. Future work focuses on optimizing pressing and matrix infiltration using chemical processes and eventually translation of this to uranium fuels. (R. Seibert, A. Nelson)

[INL] An engineering work request was submitted for design of the necessary detection system in the building. Walsh Engineering was assigned to develop the detection system drawings. A visit was made to Thermal Technologies and verification was received that materials are on schedule to be delivered to INL in early November (M. Cole) 


\subsubsection{LWR Core Materials}

[LANL] A Level 2 milestone was met through testing C26M tubing at microscale, mesoscale and larger scale testing. In addition, nanohardness testing was performed. Consistent results were obtained showing the usefulness of small-scale mechanical testing. (S. Maloy)

[LANL] Mechanical testing on C26M tubes was completed through performing ring pull and tensile testing on tubes. Data was pulled together into a report to meet one Level 3 and one Level 4 milestone. The data showed good total elongation but very little uniform elongation because of the increased dislocation density in the tubes from the last extrusion step. (S. Maloy)

[LANL] Level 3 and 4 milestones were completed including hardness testing on FeCrAl specimens as well as a milestone that compares the properties measured with nanohardness and larger scale testing. Data was compiled in two detailed reports to meet these milestones. (T. Saleh)

[ORNL] AFC Level 3 milestone M3FT-19OR020202053 titled, "Report on Exploration of New FeCrAl Heat Variants with Improved Properties," was submitted to DOE in August 2019. The report summarized optimization efforts of ATF wrought $\mathrm{FeCrAl}$ alloys to improve various properties, including microstructure stability, processability, ductility, and oxidation resistance, through minor alloying additions. (Y. Yamamoto)

[ORNL] Preliminary evaluation results of thermophysical properties for C26M2 (Fe-12Cr-6Al-2Mo$0.2 \mathrm{Si}-0.03 \mathrm{Y}$, wt. \%) were reported in the Level 3 report above. The issues in the specific heat capacity measurements were identified which came from a reaction with the sample container. Replacement of the container is currently in progress, and the measurement will be restarted in September 2019. (Y. Yamamoto)

[INL] The milestone titled, "Report on ATF ODS thin-wall cladding joining technique development," was completed. (J. Gan)

\subsubsection{LWR Irradiation Testing \& PIE Techniques}

[INL] The mechanical design of the closure plate is nearly complete. The T\&FR document is being finalized. A contract was placed to purchase the beryllium needed to build a booster element basket. (T. Maddock)

[INL] ATF-2 was irradiated in ATR cycle 166B reaching 172 effective full power days by the end of September. The ATF-2B final design review and the Level 2 milestone M2FT-19IN02203011 titled, "Design approved for modifications to the ATF-2 test train for BWR rodlets," were completed on schedule on September 30, 2019. The new design establishes the new safety basis for irradiation of boiling water reactor (BWR) type rodlets in Tiers 3 and 4 and a fully fueled test train with pressurized water reactor type rodlets in Tiers 1,2, and 5 in the Advanced Test Reactor Loop 2A at more prototypical pressure and temperature. ATF-2B is on-schedule for reconfiguration in October 2019 and beginning irradiation in November 2019. (G. Hoggard)

[INL] Preliminary design and analysis efforts to support new ATF-1 scope for Framatome are making progress. Fabrication of some capsule components and gauges has begun. Preliminary enrichments and temperature data have been derived and have informed the design specifications of the fuel rodlet. Conceptualization of a new ATF material test called Cladding Creep has begun. Scoping for these FY20 efforts is complete. The 166A irradiation cycle is nearly complete. Preparations for the 166B cycle will be minimal as there is not any planned reconfiguration of the existing capsules. (C. Murdock)

[INL] Profilometry data on five ATF-1 rodlets have been gathered. One rodlet (ATF-W01) contained U3Si2 fuel and Zirlo cladding, two rodlets (ATF-WB2 and ATF-WB6) had UN-U $\mathrm{Si}_{2}$ fuel and Zirlo cladding. The last two (ATF-L41 and ATF-L44) had UN-U $\mathrm{Si}_{5}$ fuel and FeCrAl Kanthal-AF cladding. 
The first three rodlets were sponsored by Westinghouse, whereas the last two rodlets were sponsored by LANL. (F. Cappia)

[INL] PIE results on ATF-06, ATF-08 and ATF-73 capsules and contained rodlets were presented at the TopFuel Conference in Seattle. (F. Cappia)

[INL] A report titled, "Post-irradiation Examination of the ATF-1 Experiments - 2019 Status," was completed and submitted in order to satisfy the Level 2 Milestone titled, "Update Report on ATF-1 PIE," from ATF PIE FT-19IN02020303. This report combines PIE results from three different UO2-FeCrAl irradiation experiments, and one $\mathrm{U}_{3} \mathrm{Si}_{5}$-Kanthal $\mathrm{AF}$ experiment. In addition, non-destructive PIE on five other ATF-1 capsules were reported. (F. Cappia)

[ORNL] A manuscript titled, "Separate effects irradiation testing of miniature fuel specimens," (C. Petrie, J. Burns, A. Raftery, A. Nelson, and K. Terrani) was published in the Journal of Nuclear Materials Volume 526 (2019) p. 151783. The manuscript describes a new separate effects irradiation testing capability utilizing miniature fuel specimens irradiated in the permanent reflector of the High Flux Isotope Reactor (HFIR). The advantages of this approach are described, including a greatly simplified, flexible experiment design that allows for economical, high-throughput irradiation testing of a wide range of nuclear fuels. The high neutron flux in HFIR allows for accelerated burnup accumulation and the small size of the fuel minimizes fuel temperature gradients and nearly decouples fuel temperature from fission rate. (C. Petrie)

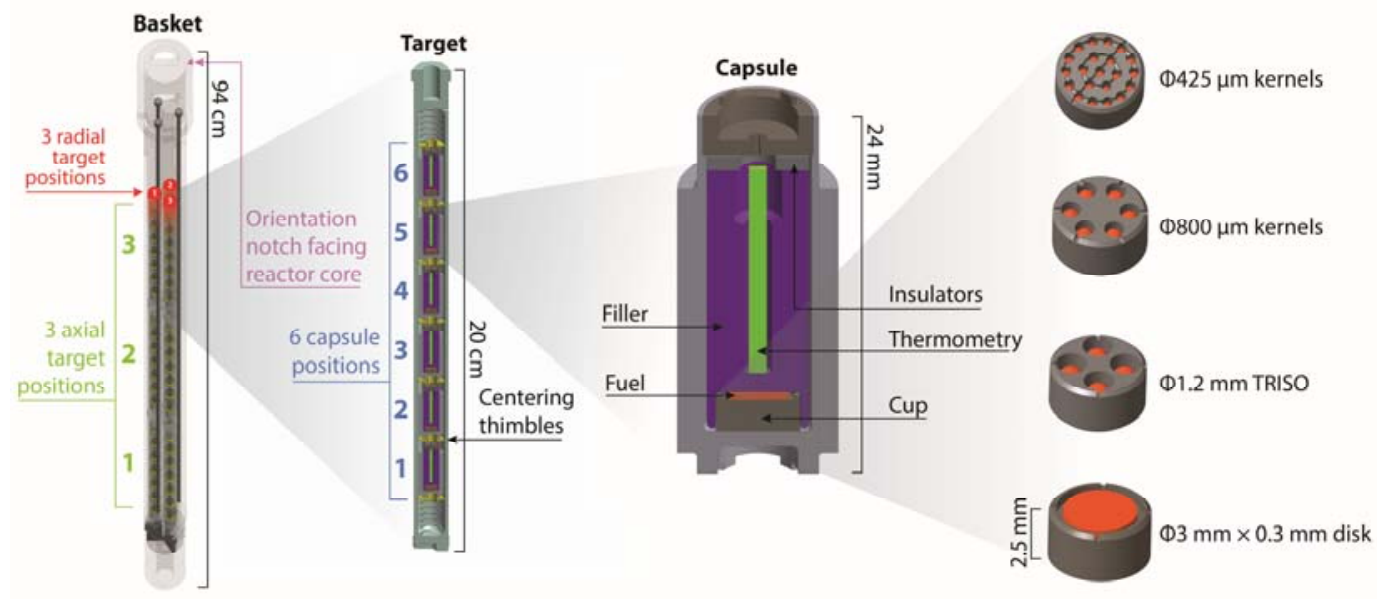

Figure 1. MiniFuel experiment configuration.

[ORNL] A Level 3 Milestone report titled, "Progress Report on Irradiation Testing of ODS FeCrAl and FeCr Alloys," (C. Massey, A. Le Coq, and C. Petrie) was submitted on September 20, 2019. The report summarizes a High Flux Isotope Reactor (HFIR) irradiation experiment to assess the irradiation stability of various oxide dispersion strengthened (ODS) $\mathrm{FeCr}$ and $\mathrm{FeCrAl}$ alloys either in light water reactor or advanced reactor operating temperature regimes. This irradiation campaign allows three variants of thinwalled ODS tubing - 14YWT, OFRAC, and CrAZY - with differing geometries to be irradiated at different target temperature regimes. To accomplish this, individual capsule assemblies were designed to accommodate either the ORNL-produced tubes or the LANL-provided tubes. This irradiation campaign will provide the first neutron irradiation study of these ODS alloys pilgered into thin-walled tube forms, which is expected to provide meaningful data about the evaluation of the microstructure (and the precipitate dispersion) for each alloy under different irradiation conditions. (C. Massey) 


\subsubsection{LWR Fuel Safety Testing}

[INL] The milestone to issue a summary report on separate effects testing for ATF fuels was completed. Work on BISON analysis of historic TREAT experiments continued. Models were developed and their viability continue to be assessed for this work. Pre-hydrided zirconium sample work continues to be developed. All hydrided samples were sectioned, potted, polished, etched, and photographed. Hydrogen concentration and orientation was assessed in most of the samples to enable a path forward for FY20 development and testing to be created. (L. Emerson)

[INL] Two Level 3 Milestones, "Issue a summary report on LOCA fuel performance benchmarking efforts," and "Issue a summary report on RIA fuel performance benchmarking efforts," both due on September 30, 2019, were completed ahead of schedule on September 20, 2019. (T. Pavey)

[INL] The final Level 3 Milestone report summarizing R\&D highlights and activities for FY19 was completed. An optical-fiber linear displacement sensor was successfully built and tested. (K. Bowman)

[INL] The Level 3 Milestone titled "Issue a summary technical report on qualification of PIE capability techniques," due on September 27, 2019 was completed ahead of schedule on September 17, 2019. (T. Pavey)

[ORNL] The Level 3 AFC Milestone report M3FT-19OR020204083 titled, "Summary Report on Effect of Cladding Segment Length on Burst Behavior," was successfully completed on September 20, 2019. The technical report titled, "Progress Report on Length Dependence of Severe Accident Test Station Integral Testing," summarizes the progress made to determine the compatibility of reduced length samples for an integral loss-of-coolant accident (LOCA) test using ORNL's Severe Accident Test Station (SATS). Currently the standard test can subject a 12-inch long cladding sample to design basis accident relevant conditions including internal pressure, steam oxidation, temperatures up to $1200^{\circ} \mathrm{C}$, and water quench. The 12-inch sample size limits the amount of testing that can be performed on irradiated ATF materials and is not practical for HFIR irradiations. This work successfully demonstrated similar burst behavior across various sample lengths as short as 4". (K. Linton)

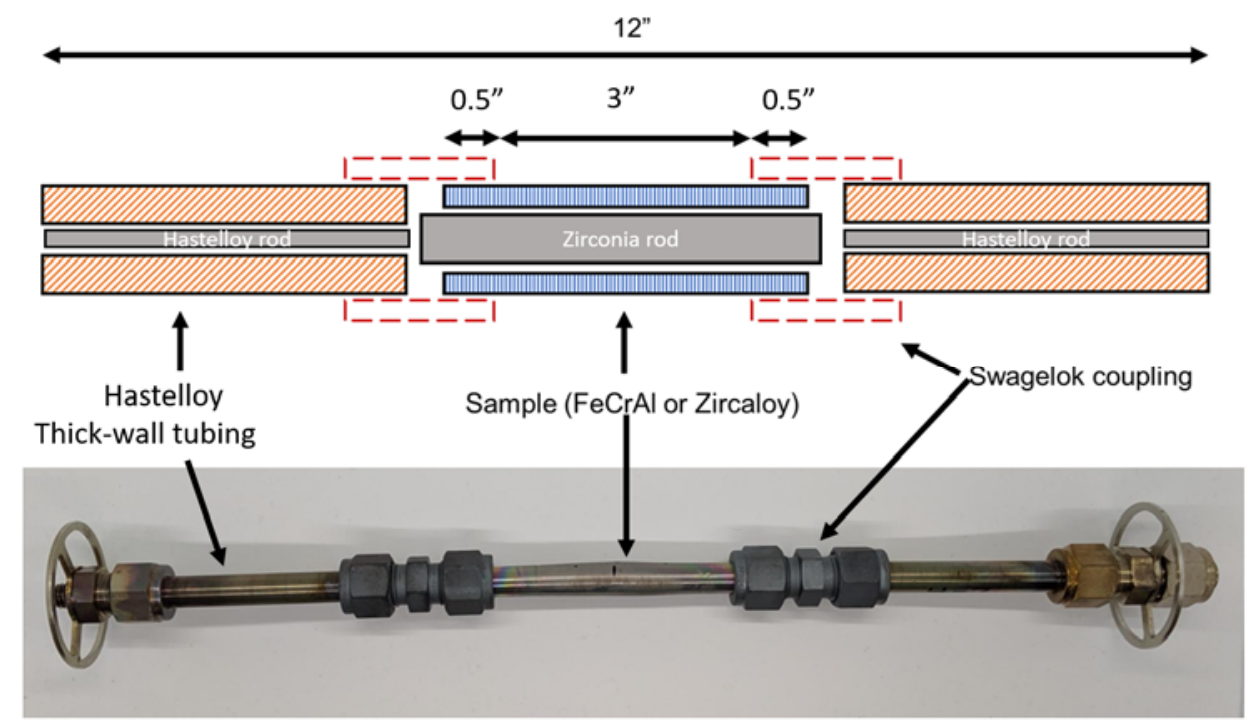

Figure 2. LOCA test train with a reduced length cladding segment (4") showed similar burst behavior as the standard 12 " test segments. 
[INL] Two Level 3 Milestones, "Assemble and Prepare Next 96 Detector Assembles and Electronics for Deployment," and "Issue Report on TREAT Reactor Metrology Method Development and FY2019 Operational Support," due on September 30, 2019 were completed on schedule. (T. Pavey)

[INL] Metal Fuels information was provided to Orano to develop the Certificate of Conformance for shipping metal fuels using the BRR Cask. (T. Pavey)

[INL] The Level 3 Milestone titled, "Report/Journal article on MAMMOTH validation for MARCHSETH experiments," due September 30, 2019 was completed ahead of schedule on September 17, 2019.

[INL] The Level 4 Milestone titled, "Report on use of MAMMOTH for experiment design," due on September 30, 2019, was completed ahead of schedule on September 17, 2019. (T. Pavey)

\subsubsection{LWR Computational Analysis \& Fuel Modeling}

[INL] The milestone report titled, "Status report on ATF performance modeling using BISON: Effect of diamond doping on the fission gas release in $\mathrm{UO}_{2}$ fuel irradiated to $7.2 \mathrm{GWd} / \mathrm{tHM}$," was submitted on schedule. (P. Medvedev)

[BNL] The deliverable report for BNL M3FT-19BN020205022 titled, "Assessment of Core Performance of Advanced LWR Fuel Concepts in Normal and Accident Conditions - Summary Report on FY19 Activities," was submitted on schedule (9/27/2019). (M. Todosow, L-Y. Cheng, A. Cuadra)

The report describes the following major activities:

- The impact of coating fuel pellets and/or individual grains to mitigate the fuel/coolant interactions for water-reactive high-density fuel phases, such as $\mathrm{U}_{3} \mathrm{Si}_{2}$, and $\mathrm{UN}$, that have been proposed by LANL.

- An assessment of control rods with improved thermo-chemical-mechanical properties compared to "conventional" silver-indium-cadmium (AIC) but still provide the requisite reactivity control functions

- Initial neutronic analyses of full- and half-diameter $\mathrm{UO}_{2}$ pellets in an ATR irradiation capsule. An objective of this approach is to accelerate the burnup of fuel samples by using reduced diameter fuel pellets to increase the power density.

- Development/application of an approach based on the DAKOTA code for Uncertainty Quantification (UQ) and Sensitivity Analyses (SA) for use with accident analyses with the TRACE systems code

[BNL] Examination of the previously reported uncertainty analysis for the loss-of-offsite power accident (LOOP) indicates that the magnitude of the peak cladding temperature (PCT) is also a function of the initial steady-state condition (see Figure 3 below). As a way to compensate for the potential bias from the initial cladding temperature, an alternate FOM is defined. Instead of using the PCT value directly, the FOM is defined as the maximum rise in cladding temperature from the start of the transient,

Alternate FOM $=$ Maximum of $\{($ Transient cladding temperature $)-($ Initial Cladding temperature $)\}$

Using this alternate FOM of maximum net rise in cladding temperature the 95/95 limit was calculated to be $6.2827 \mathrm{~K}$ and the corresponding PCT was $619.14 \mathrm{~K}$, which is comparable to the 95/95 limit of 619.65 $\mathrm{K}$ when the PCT values were used directly in the statistics. The partial rank correlations for the maximum net rise in cladding temperature also exhibit the same dependency on the sensitivity parameters as the case of using the PCT directly. This exercise suggests that the initial cladding temperature does not drive the PCT directly. (L.-Y. Cheng) 


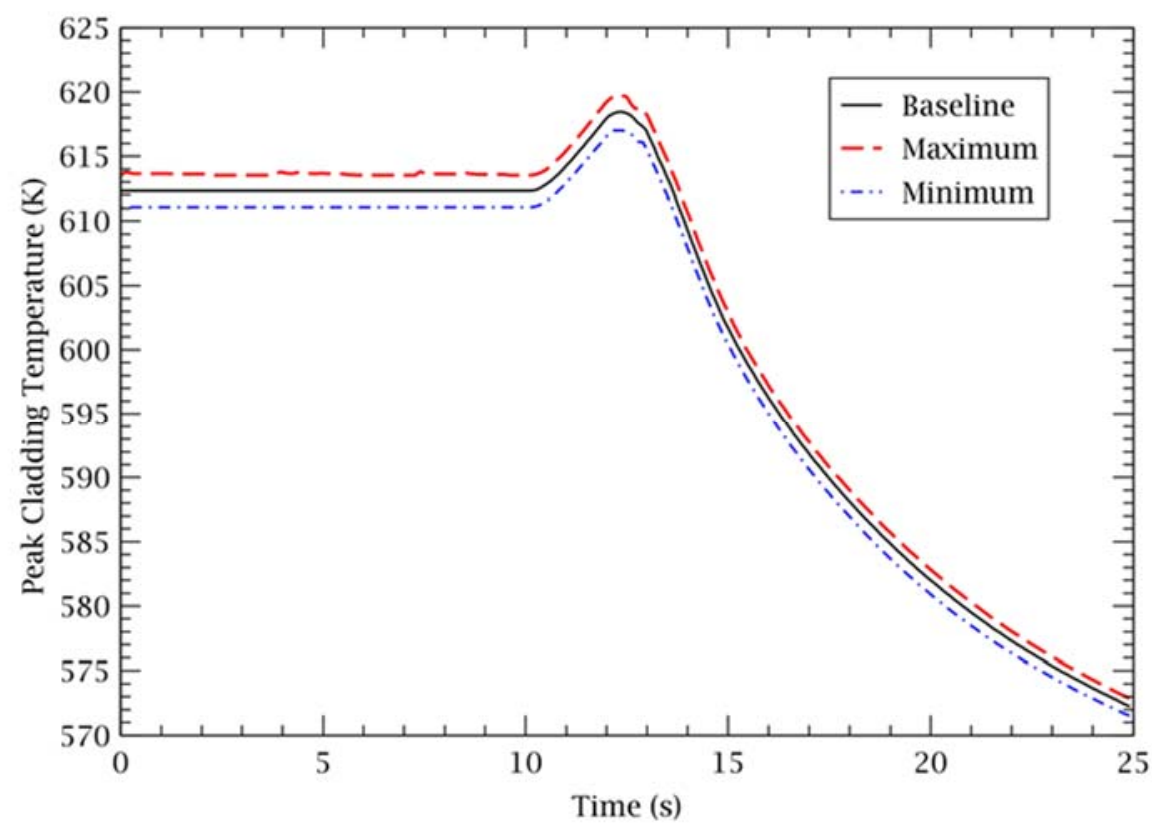

Figure 3. Comparison of peak cladding temperature among sensitivity cases.

[ORNL] Fuel performance modeling activities during September focused on the completion and delivery of two milestones, M3FT-19OR0202050304 focused on demonstrating the analysis capability of BISON for modeling coated cladding for accident tolerant fuel applications, and M2FT-19OR020205031 describing the results of multi physics modeling analysis of the behavior of SiC-composite coated fuel rods in addition to BWR channel box performance. In October, two presentations are scheduled for the Materials in Nuclear Energy Systems (MiNES) Conference, one of which is an oral presentation, "Modeling the thermal-mechanical behavior of SiC-SiC cladding using BISON", and second is scheduled for poster presentation, "Deformation Behavior of SiC-SiC Channel Box in Boiling Water Reactor Environment". Modeling efforts continue to focus on coated cladding and silicon carbide composite fuel cladding. (B. Wirth)

\subsection{Advanced Reactor Fuels}

\subsubsection{AR Fuels}

[INL] The Level 2 Milestone titled, "Demonstrate machining capability for plutonium bearing fuel alloys," was completed. To complete this milestone, a 0.75 in. $(19.05 \mathrm{~mm})$ long U-20Pu-10Zr fuel slug was turned on a lathe to approximately $0.192 \mathrm{in}$. $(4.88 \mathrm{~mm})$ diameter. After turning, a 0.116 " $(2.95 \mathrm{~mm})$ drill bit was used to drill a hole through the length of the fuel slug. This shows the capability to fabricate test pieces for irradiation testing of transuranic bearing fuels. The fuel slug fabricated is shown in Figure 4 below. Based on this success the AFC-4G will include 2 separate geometries of ternary fuel which will be machined to final size and shape. Although the test will not be irradiated until FY21 it is planned to fabricate the test in FY20. (R. Fielding) 
Figure 4. Fabricated fuel slug.

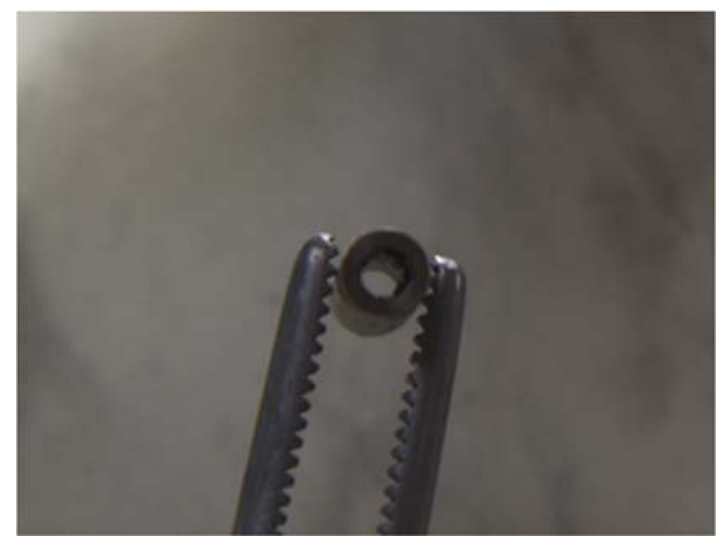

[INL] Several HT-9 cladding tubes were co-drawn with either vanadium or zirconium rod down to 0.115 in $(2.92 \mathrm{~mm})$ outer diameter with a 0.009 in. $(0.23 \mathrm{~mm})$ wall thickness. Samples were taken from the $\mathrm{Zr}$ co-drawn tubes and section for metallographic examination to determine the amount of mechanical bonding seen from the co-drawing process. The tube with the best bond will then be used to produce zirconium lined cladding tubes to be used in the irradiation test. (R. Fielding)

[INL] Dr. K. Gofryk published an article titled, "The Grain-Size Effect on Thermal Conductivity of Uranium Dioxide," in the Journal of Applied Physics. The paper expands the fundamental understanding of thermal properties in actinides which will facilitate better understanding of fuel fabrication and behavior in the reactor. (J. Giglio)

\subsubsection{AR Core Materials}

[LANL] A Level 3 milestone was met through completing hardness tests on previously shear punch tested HT-9 samples that were irradiated in the BOR-60 reactor. Data showed hardening similar to what was observed in the shear punch testing. (B. Eftink)

[PNNL] Milestone M3FT-19PN020302021, titled, "Conduct Ion and Neutron Irradiation Effects Studies of Ferritic/Martensitic Steels and Write Report," was completed on time. This report included the results of two different studies. One study worked toward optimization of ion irradiation temperature to produce a more neutron-irradiation like microstructure. Irradiation effects studies are needed to understand how the mechanical properties of a material evolve with received irradiation dose. Ion irradiations can be used to estimate some aspects of the mechanical properties through quantitative analysis of the microstructure features that form. An existing theory suggests that conducting ion irradiations at a temperature slightly higher than the neutron irradiation temperature of interest can produce microstructures in the ion irradiated material that are more similar to the material after neutron irradiation. It was found that this may work for some aspects of the microstructure, but not all. However, the microstructure features that were absent after optimization of the ion irradiation temperature are known to have little effect on mechanical properties of a material, so although the temperature optimization didn't make the ion irradiation induced microstructure identical to the neutron irradiation, the features that were missing don't strongly impact mechanical properties. Thus, the research on ion irradiation techniques at PNNL continue to indicate that ion irradiation remains a useful tool for screening of materials. The second topic covered in this report was tensile testing of three heats of HT-9 that were irradiated in ATR at 290, 360, and $430^{\circ} \mathrm{C}$. It was found that all three materials increased in strength with irradiation temperature while ductility was reduced by roughly the same amount at all irradiation temperatures. One heat had substantially higher strength than the other two heats, and initial microstructure exams suggest that this is due to a much higher content of G-phase precipitates in this heat. The higher G-phase content appears to 
be due to the high content of the elements that make up G-phase (Ni, Si, Mn), however the composition of this heat was still roughly in specification for this alloy. (M. Toloczko)

[PNNL] Two out of three of the 9Cr alloys for milestone M4FT-19PN020302022 titled, "Conduct 9Cr Alloys Development and Testing at PNNL and Write Report," have been completed. The third alloy is expected to be completed by mid-October, and then initial microstructure exams focusing on evaluating crystal structure, grain size, and grain boundary carbide coverage will be performed and reported for the December report. (M. Toloczko)

[PNNL] The memo report (M4FT-19PN020302032), titled, "Preparation for the fracture toughness testing of irradiated core materials," was completed and submitted. The fracture toughness testing of irradiated ferritic-martensitic steels at a hot cell facility is one of the key testing and evaluation activities planned in the work package, and the FY 2019 activity includes the development of hardware to test dozens of MATRIX-irradiated disk compact tension (DCT) specimens. These specimens, which were irradiated to high doses, are expected to be available in the next fiscal year. Therefore, the testing procedure and specimen jigs have been prepared during this fiscal year. This memo is to report the preparation status of the hot cell testing with the miniature DCT specimens. (T.S. Byun)

[PNNL] As part of the program to advance the technology associated with fabricating tubing from difficult-to-fabricate materials, the PNNL rolling mill has been modified so that it can perform pilgering of thick-wall tubes. This capability to pilger thick-wall tubes into finished thin-wall tubing establishes a unique R\&D capability within the DOE complex.

The plan for FY-20 is to build upon the two pilgering runs on 14YWT completed in FY-19 by extending the length of the pilgered tube. Current plans are to pilger both a 24 inch and a 36-inch thin-wall tube of 14YWT, and possibly a tube of FeCrAl. This will require a longer actuator and longer mandrels. The longer actuator has been procured and is being installed on the rolling mill. The installation in progress is shown in Figure 5 below. It is not yet ready for operation as the installation needs to be completed and programming must be done to the I\&C system controlling the actuator. (R. Omberg)

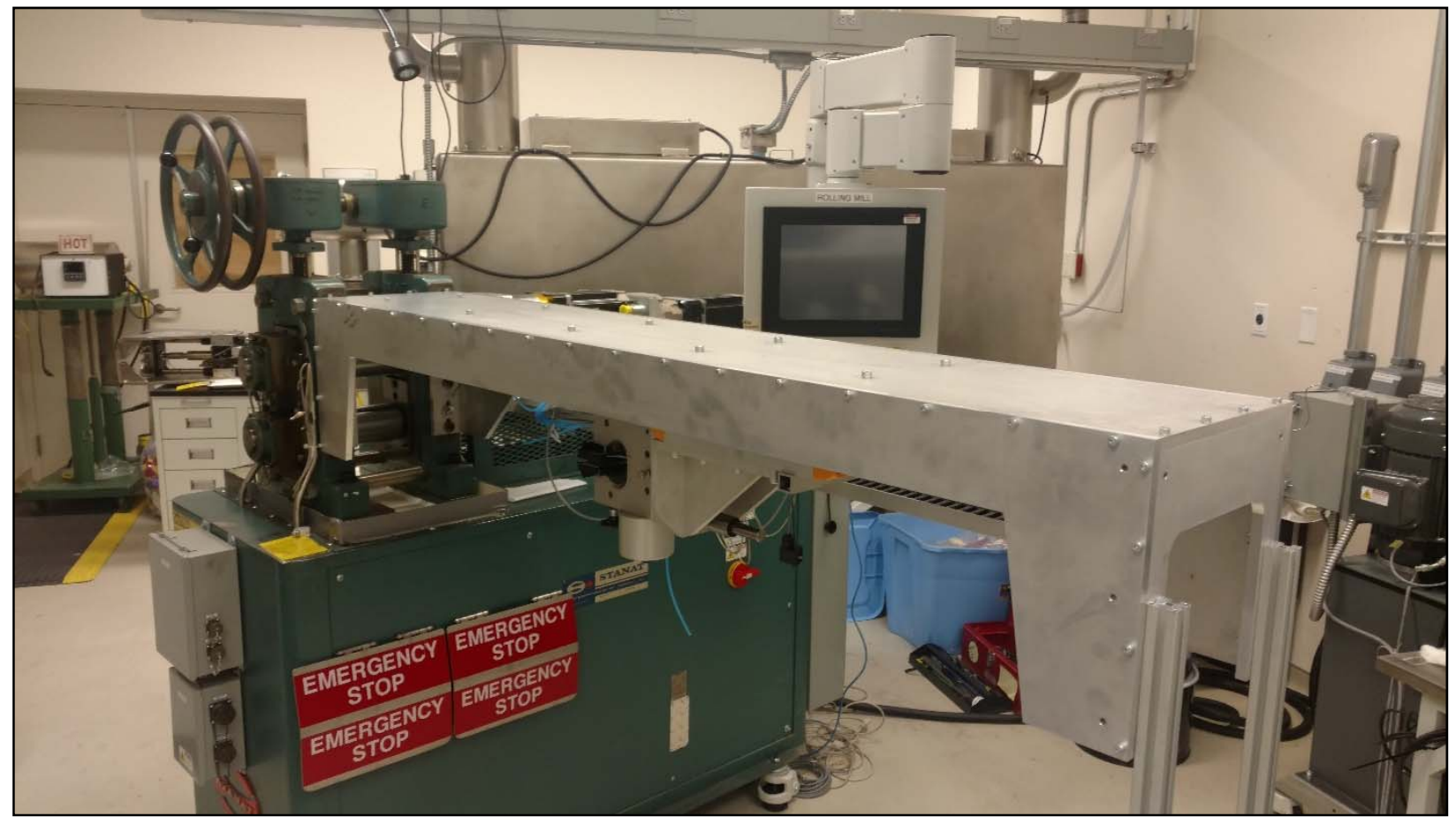

Figure 5. Longer actuator during installation on the rolling mill. 
[LANL] A Level 2 milestone was met through producing tubes of 14YWT for future irradiations in ATR. The tubes were produced through two different methods. In one method three tubes were produced through EDM machining of the tubes from an original extruded rod. The exact dimensions were met through this method. In the second method a tube was produced through hydrostatic extrusion. The dimensions were slightly smaller than the required diameter but a uniform, extruded rod was produced. These tubes will be characterized in next fiscal year. (S. Maloy)

[LANL] High dose ion irradiations were completed on HT-9 at 450C to doses up to 600 dpa. Data showed swelling at rates similar to those observed for previous FFTF irradiations. This was pulled together into a report to meet a Level 3 milestone. (S. Maloy)

[ORNL] The $3^{\text {rd }}$ HPTR (High Precision Tube Rolling) cold roll of the four tubes of OFRAC was completed by Nippon Fuel Development (NFD), Japan. Small cracks formed on the OR8 and OR12 tubes and were removed. The lengths of the tubes have been increased to $\sim 38 \%$ of the initial lengths of each master tube. The significance of this next thin wall tube fabrication attempt is that the final dimension of the thin wall tubing will be $6 \mathrm{~mm}$ outer diameter, $0.5 \mathrm{~mm}$ wall thickness and lengths estimated to be more than $2 \mathrm{~m}$. (Hoelzer/Massey)

[ORNL] The extrusion press was repaired, and the two remaining cans filled with ball milled powder of the new 14YWT heats are in the schedule to be extruded in October. The three new heats of 14YWT will provide information about the role of lower $\mathrm{W}$ level of $1 \%$ and the effect of different titanium levels $(0.2$, 0.3 and $0.4 \%$ ) on improving the balance of mechanical properties compared with the past composition of $14 \mathrm{YWT}$ that contained 3\% W and $0.4 \%$ Ti. (D. Hoelzer)

\subsubsection{AR Irradiation Testing \& PIE Techniques}

[INL] The FAST-1 group experiments continue to make progress toward concluding the final design phase. The final enrichments, temperature and structural analyses are nearing completion. Most analysis is complete and is in technical check. The final design review is expected to kick off in the next six weeks. Fabrication is making progress for outer capsule components. The inner capsule components have yet to begin. Scoping for the FAST-2, 4F/4G, and Booster I-position studies as FY2020 efforts is complete and is ready to kick-off for the FY2020 fiscal year. The programmatic analysis for the current irradiation cycle completed late due to resource availability. The 166A irradiation cycle is near completion and is expected to conclude the first week of FY2020. Preparations for the 166B irradiation cycle have started and will support on-time insertion in the reactor. (C. Murdock)

[INL] A Level 2 milestone report was completed and issued. This report described the ongoing postirradiation examination on EBR-II legacy fuel pins that are of paramount importance to complement ATR irradiation. The report, authored by L. Capriotti and J. Harp, is titled, "Status PIE Report on Legacy EBR-II and FFTF Metallic Fuel Experiments,” INL/EXT-19-55847. (L. Capriotti)

[INL] Burnup chemistry on X430-T653 and X521-G594 pins is completed and the data are being processed and reviewed. (L. Capriotti)

[INL] Development of the software associated with the new furnace fixture continued. The FY20 plan associated with this scope was developed. (M. Cole)

\subsubsection{AR Fuel Safety Testing}

[INL] Design work continued on the heat sink module with various options and trade-offs being considered amongst the team. Sketches for the design were created and vetted for viability. (L. Emerson) 
[INL] The Level 3 Milestone titled, "Issue a summary report on Separate Effects Testing for ATF fuels," due on September 6, 2019, was completed ahead of schedule on September 3, 2019. (T. Pavey)

[INL] The report titled, "Select Transient Metallic Fuel Bison Benchmarks," was completed. (T. Pavey)

\subsubsection{AR Computational Analysis \& Fuel Modeling}

[INL] The milestone report titled, "Status report on BISON development for fast reactor fuels," was completed. (P. Medvedev)

\subsection{Capability Development}

\subsubsection{Fuels}

[INL] The Level 2 milestone report (FT-19IN02040101) titled, "Demonstrate Property Measurement on Irradiated Fuel in IMCL," was completed on time and submitted with the QA cover sheet. The goal of this work was to install a laser flash analyzer (LFA) and a thermal conductivity microscope (TCM) into the Thermal Properties Cell located in IMCL and take the first measurements of irradiated metallic fuel. In order to demonstrate the successful installation of this new measurement capability, the U-Zr fuel system. Specifically, U-10 wt.\% Zr, was chosen as the first material to be evaluated due to its importance to the NTRD program. The results of the first four measurements (2 as-built, 2 PIE) conducted in the TPC on the LFA and the TCM are given in this report. Figure 6 below shows the newly installed instrumentation in the TPC. Fresh fuel samples from the same lot of fuel fabrication were also measured as a baseline instrument verification and comparison to the irradiated fuel data.
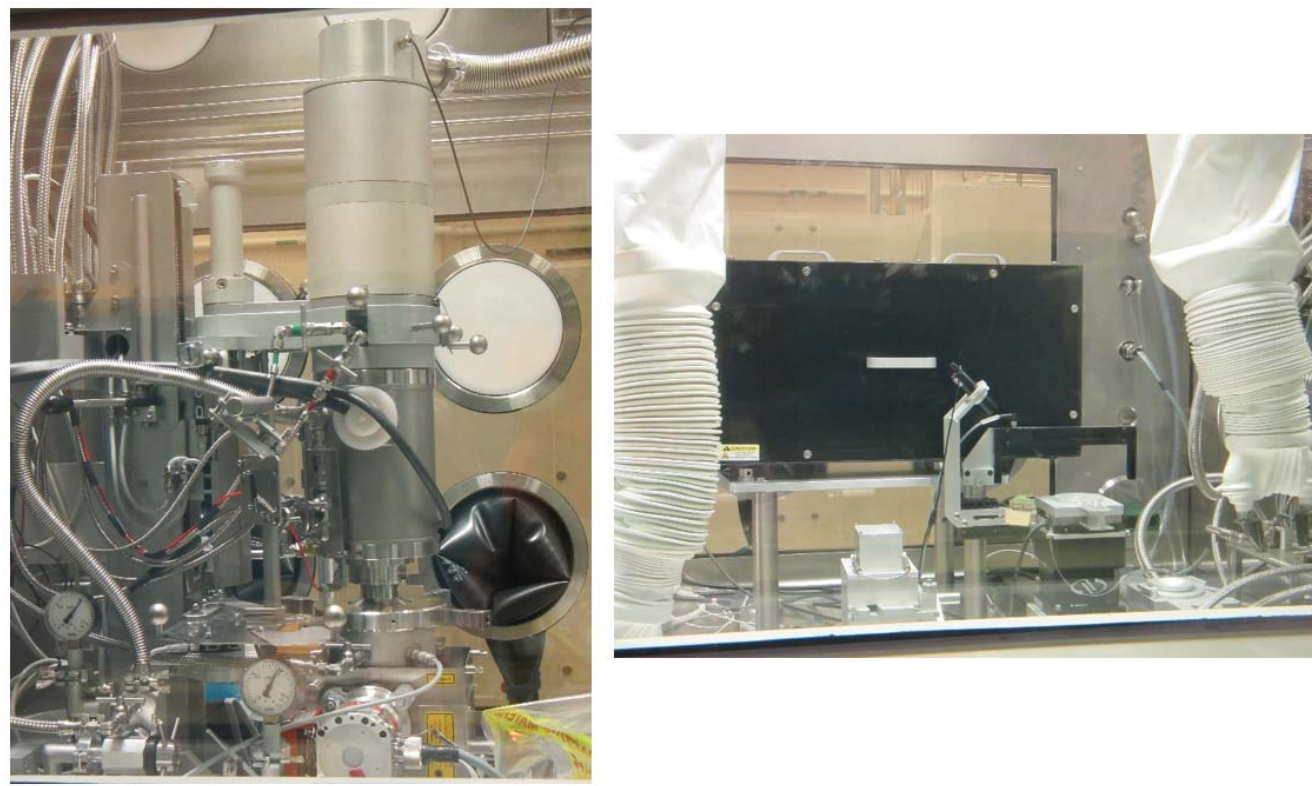

Figure 6. Laser Flash Analyzer (left) and Thermal Conductivity Microscope (right) installed in the TPC.

This demonstration revealed many actions for future study. Further work in identifying experiment variables, error propagation, and sample preparation will be valuable in improving upon this new capability of thermal diffusivity and thermal conductivity as applied to post-irradiated fuels and materials. Future work planned in FY20 includes design improvement of the sample holders and preparations methods for both the LFA and TCM measurements. (M. Cole) 
[INL] The milestone status report (FT-19IN02040102) titled, "Status Report on Photothermal Radiometry Development," was submitted with the QA cover sheet. (D. Hurley)

\subsubsection{TREAT Testing Infrastructure}

[INL] The conceptual design review on I-position loop was completed. The Level 3 Milestone titled, "Conduct conceptual design review on I-Position loop design," due on September 27, 2019, was completed ahead of schedule on September 23, 2019. (T. Pavey)

For more information on Fuels contact Steven Hayes (208) 526-7255. 


\section{MATERIAL RECOVERY AND WASTE FORMS DEVELOPMENT \\ 2.1 Process Chemistry and Integration}

[INL] The milestone titled, "Evaluate the aqueous phase radiation chemistry and radioprotective mechanisms of aqueous miscible ligand derivatives to aid the future design of radioprotective extractants," (M2FT-19IN030102012) was completed. This research focuses on evaluating the radiation robustness of a series of aqueous miscible CMPO analogues (phosphonic acids), to further our understanding of activated radioprotection in a medium in which fundamental radiation chemistry is well established. A draft manuscript for the M2FT-19IN030102012 milestone was completed and submitted. The draft manuscript was converted into journal format and submitted to Radiation Physics and Chemistry (latest impact factor: 1.984) as a manuscript, titled "Probing Activated Radioprotection of Simple Hydrophilic Phosphonic Acids in Aqueous Solution.” (G. Horne)

[INL] A manuscript, titled, "Effect of Chemical Environment on the Radiation Chemistry of N,N-di-(2ethylhexyl)butyramide (DEHBA) and Plutonium Retention," has been published in Dalton Transactions (latest impact factor: 4.052), in collaboration with the French Alternative Energies and Atomic Energy Commission (CEA) and California State University Long Beach: Dalton Trans., 2019, 48, 14450, DOI: 10.1039/c9dt02383f (https://pubs.rsc.org/en/content/articlelanding/2019/dt/c9dt02383f). The presented work investigates the radiation robustness of the monoamide ligand N,N-di-(2-ethylhexyl)butyramide (DEHBA), and its two major degradation products, bis-(2-ethylhexyl)amine (b2EHA) and N-(2ethylhexyl)butyramide, (MEHBA), as a function of absorbed dose and chemical environment (single phase in n-dodecane, and biphasic in contact with 0.1 or $3.0 \mathrm{M}$ nitric acid). Irradiated solutions were then evaluated by a series of distribution ratio experiments, using tracer uranium and plutonium solutions, to determine the effect of ligand degradation on envisioned process performance.

An additional manuscript titled," DEHBA (di-2-ethylhexylbutyramide) gamma radiolysis under spent nuclear fuel solvent extraction process conditions," was submitted to Radiation Physics and Chemistry (latest impact factor: 1.984) as a special edition proceedings issue for the 14th Tihany Symposium on Radiation Chemistry (http://www.tihany.kfki.hu/). (G. Horne)

[INL] A manuscript titled, "Gamma radiolysis of hydrophilic diglycolamide ligands in concentrated aqueous nitrate solution," has been submitted to Dalton Transactions (latest impact factor: 4.052), in collaboration with the Forschungszentrum Jülich and California State University Long Beach. This research focuses on investigating the radiolytic robustness of a series of novel hydrophilic diglycolamides (DGAs) in both aqueous and organic media, representative of envisioned process conditions: TEDGA, MeTEDGA, $\mathrm{Me}_{2}$ TEDGA, and TPDGA. The DGAs have shown considerable potential as candidates for the co-extraction of trivalent actinides and lanthanides, due to their structural flexibility and subsequent solubility, selectivity, and extraction capabilities.

The INL radiolysis test loop system has been employed to evaluate the effects of gamma radiolysis and acid hydrolysis on the stability and performance of advanced separation processes. Recent work at Idaho National Laboratory on the ALSEP process has focused upon the development of solvent washing schemes. A report describing the implementation of the proposed ALSEP caustic solvent wash in the INL radiolysis test loop was issued September 27, 2019. The report documents completion of Milestone M3FT-19IN0301020111 titled, "Complete test loop irradiation testing of ALSEP flowsheet with solvent reconditioning." 

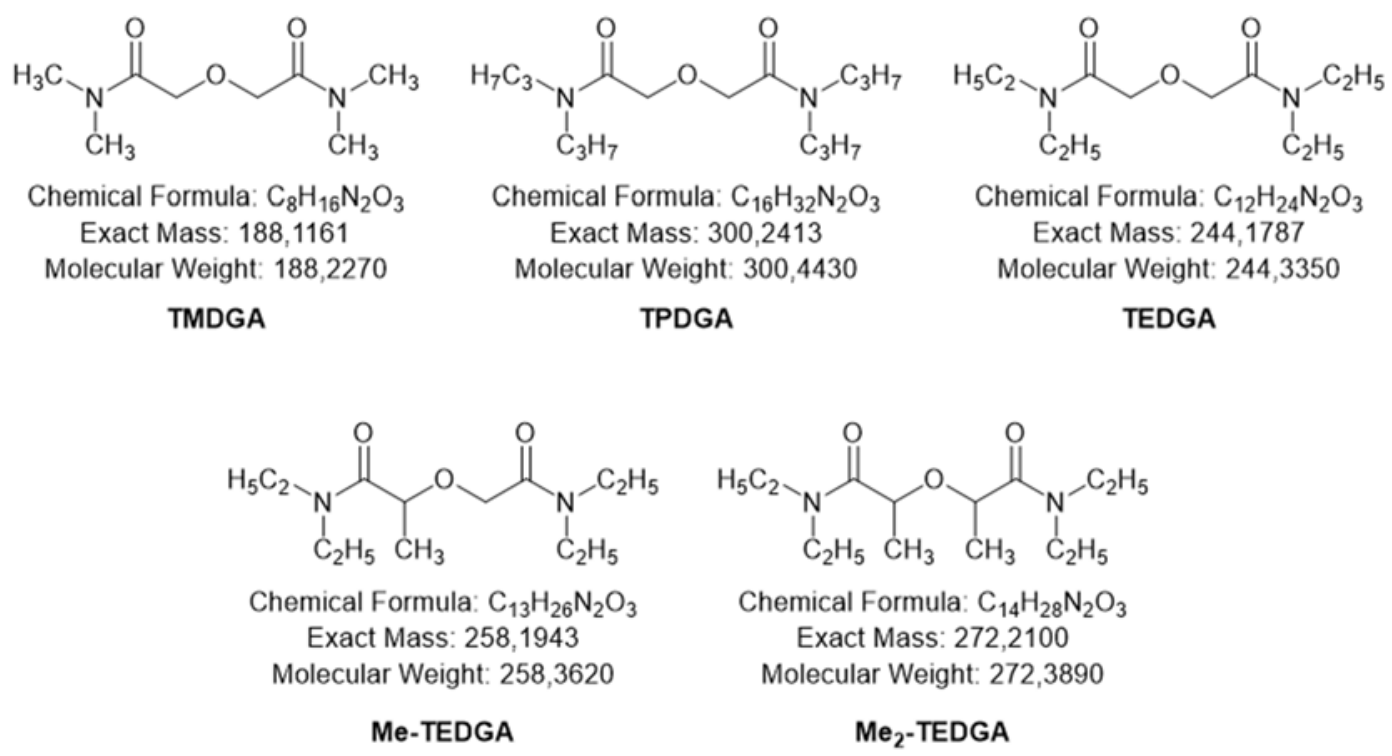

The ALSEP process solvent is comprised of a combination of the solvating extractant N,N,N',N'-tetra(2ethylhexyl)diglycolamide (T2EHDGA) and the cation exchanging extractant 2-ethylhexylphosphonic acid mono-2-ethylhexyl ester (HEH[EHP]) dissolved in dodecane. The actinides and lanthanides are coextracted from a relatively high nitric acid concentration and the actinides are selectively stripped using a carboxylic acid buffered aminopolycarboxylic acid solution.

In order to evaluate the effectiveness of the proposed ALSEP caustic solvent wash, a series of test loop irradiations were performed, and the irradiated solvent treated using the reconditioning section of the INL test loop. Batch contact flowsheet tests and compositional analysis of the irradiated and reconditioned ALSEP solvents indicate that the proposed ammonium carbonate solvent wash would be an effective means of removing products of radiolytic degradation from the ALSEP process solvent. (D. Peterman)

[INL] Novel aminopolycarboxylate complexant containing four soft donor amine sites was synthesized at ORNL and characterized at INL, targeting an enhanced trivalent actinide/lanthanide differentiation. This strategy seeks to enhance the complexation strength for trivalent actinides, relative to trivalent lanthanides of equivalent charge density. The novel reagent triethylenetetramine- $\mathrm{N}, \mathrm{N}^{\prime \prime \prime}$-diethyl- $\mathrm{N}, \mathrm{N}^{\prime}, \mathrm{N}^{\prime \prime}, \mathrm{N}^{\prime \prime \prime}-$ tetraacetic acid, H4ttdta, is octadentate, and resembles H6ttha (triethylenetetraamine-N,N,N',N", $\mathrm{N}^{\prime \prime \prime}, \mathrm{N}^{\prime \prime \prime}-$ hexaacetic acid), but two $\mathrm{N}$-acetate pendant arms at terminal ends are replaced by $\mathrm{N}$-ethyl groups. Ligand protonation was studied using potentiometry, and complexation of $\mathrm{Nd} 3+, \mathrm{Eu} 3+$ and $\mathrm{Am} 3+$ with $\mathrm{H} 4 \mathrm{ttdta}$ was studied using potentiometry and spectroscopy. The complexometric studies show evidence of protonated complexes, dinuclear complex, together with a conventional ML species. Changes in the metal ion coordination sphere were monitored using fluorescence lifetime decay measurements, showing a profound change in metal hydration around $\mathrm{pCH} \sim 4$. Relative to H6ttha, the chelate stability of the ML complex was decreased as expected from a reduced ligand denticity. Spectroscopic studies on the complexation of $\mathrm{Nd} 3+$ and $\mathrm{Am} 3+$ by $\mathrm{H} 4 \mathrm{ttdta}$ indicate a substantial increase of $\beta 101 \mathrm{AmNd}$, presumably due to the presence of four amine coordination units on the triethylenetetraamine molecular backbone. The results of this study have been summarized in the M3FT- 19IN030102014 milestone report. (P. Zalupski)

[ONRL] A work package (FT-20OR03010202) for FY20 was prepared. The annual report describing the key research accomplishments was written. Milestone M3FT-19OR030102022 was completed, a short report was sent to the program director. (S. Jansone-Popova)

[PNNL] The report titled, "Process Chemistry and Integration-PNNL: FY 2019 Summary Report," (PNNL-29119), was issued to fulfill Milestone M3FT-19PN030102031. The Process Chemistry and 
Integration effort at PNNL focused on three tasks in FY 2019: 1) coupling of microfluidics and optical spectroscopy for characterizing fuel recycling solutions, 2) participating in an Actinide-Lanthanide SEParation (ALSEP) flowsheet experiment, and 3) investigating fundamental ALSEP chemistry. A summary of each of these activities is provided in the report, and highlights are as follows:

- $\quad$ Microfluidic Optical Spectroscopy. Microfluidic devices, coupled to optical spectroscopy (absorption and Raman spectroscopy), have been developed with the focus of using these devices for characterizing solvent extraction systems related to the nuclear fuel cycle. These microfluidic devices are unique in that they can spectroscopically probe both the aqueous and organic phases simultaneously. The novel aspect of these microfluidic chips was the ability to probe the solutions in-situ using visible (vis) absorption and Raman spectroscopy. The method was demonstrated by investigating the extraction of $\mathrm{Nd}(\mathrm{III})$ from nitrate solutions using tributyl phosphate (TBP). Both the aqueous and organic phases were analyzed as they passed through the UV-vis or Raman interrogation windows. Chemometric models were developed and demonstrated to quantify the $\mathrm{Nd}$ and nitrate concentrations.

- $\quad$ ALSEP Flowsheet Experiment. Efforts in FY 2019 regarding the ALSEP experiment were restricted to consultations with researchers at FZ-J regarding the planning of the experiment. The test was originally scheduled for July 2019, but because of technical difficulties encountered at FZ-J, the test was delayed until October 2019.

- $\quad$ ALSEP Fundamental Chemistry. ALSEP is based upon a mixed extractant system containing 2ethylhexylphosphonic acid mono-2-ethylhexyl ester (HEH[EHP]) and N,N,N',N'tetra(2-ethylhexyl)diglycolamide (T2EHDGA). Under relatively high $\mathrm{HNO}_{3}$ concentration $(>2$ M), T2EHDGA co-extracts both trivalent lanthanides and actinides. Under low acid conditions $(<$ $0.2 \mathrm{M} \mathrm{HNO}_{3}$ ), the trivalent ions are extracted by HEH[EHP]. However, in between these two $\mathrm{HNO}_{3}$ regimes, the distribution ratios for the trivalent actinides and lanthanides are larger than would be expected based upon the summation of the contribution from each individual extractant. This synergic behavior between HEH[EHP] and T2EHDGA has been investigated in detail, and a paper describing this work is being drafted. (G. Lumetta)

\subsection{Waste Form Development and Performance}

\subsubsection{Electrochemical Waste Forms}

[ANL] The milestone report summarizing the results of tests completed to-date was issued. Those tests indicate the dissolution rate does not decrease due to either increasing reaction affinity as the test solutions become more concentrated or as surface layers develop. Some tests are being continued to better characterize the long-term dissolution behavior. A revised report will be issued in January 2020 as part of the FY20 work package. (W. Ebert)

\subsubsection{Glass Ceramics Waste Forms}

[PNNL] The milestone report titled, "Compile long-term static dissolution data on glass-ceramic and single-phase materials," was completed. This milestone summarizes the corrosion work performed at PNNL on the glass-ceramic materials over the past several years. (J. Crum)

[ANL] These tests are being continued into FY20 because only a few glasses have triggered Stage 3 dissolution yet. The milestone report summarizing the results of tests completed to-date is being delayed for about three weeks to include the most recent results. A revision of that report will be issued as part of the FY20 work package when the tests are completed. (W. Ebert) 


\subsection{3 lodine Waste Forms}

[ANL] The milestone report summarizing the results of tests completed to-date is being delayed for about three weeks to include the most recent electrochemical tests showing the effect of galvanic coupling between AgI dissolution and corrosion of the steel HIP can holding the mordenite waste form. These indicate the canister serves to protect against reductive dissolution of AgI. The results of these tests will provide the basis for electrochemical and immersion tests to be conducted during FY20 and modify the degradation model. (W. Ebert)

[PNNL] Milestone M4FT-19PN030105113 titled, "Method Sensitivity and Draft Report," was completed. A report on method sensitivity of dynamic leach tests for iodine waste form types was delivered. The report covered work from FY19 to evaluate the influence of material type, surface finish, sampling intervals, temperature, surface area and solution feedback on iodine waste form corrosion. (M. Asmussen)

\subsection{Domestic Electrochemical Processing}

[ANL] The report summarizing the tests completed to measure the polarization properties of engineeringscale cell that will be used to demonstrate the U/TRU co-deposition process during FY20 and to address other operational issues for that demonstration was issued. Preparations for the demonstration have been completed and large anode baskets and collection cups for the 1-kg U/REE deposits to be generated are being fabricated and installed. (W. Ebert)

\subsection{Sigma Team for Off-Gas}

[INL] Sample analysis was completed for the long-term deep-bed adsorption test that was started in April 2019 and ended in August 2019. This test was for adsorption of iodine from methyl iodide in a simulated vessel off-gas stream using silver zeolite as the sorbent in this test.

Results of that test, plus results of a prior long-term VOG test performed earlier in the fiscal year, were reported in comparison with prior INL deep-bed test results and iodine adsorption test results from ORNL in the joint ORNL/INL report titled, "Iodine Retention of Long-chain Organic Iodides on Silver-based Sorbents under DOG and VOG Conditions," ORNL/SPR-2019/1359, INL/EXT-19-55999, which met a Level 3 milestone for both labs on September 30, 2019. Summary results of this report include:

- Iodine adsorption rate measurements as a function of iodine speciation and hydrocarbon chain length and concentration, in terms of the depth of the mass transfer zone and rate of decrease in the gaseous iodide concentration (from deep-bed tests) and rate of adsorption on the sorbent (from thin-bed tests), and for silver zeolite and silver Aerogel sorbents.

- Preliminary data on the adsorption capacity for iodine for the two sorbents for diatomic iodine and organic iodides that were tested. Results from the two labs are compared. Results indicate that once the iodine loading is normalized to Ag content, both AgZ and AgAerogel have about the same capacity, depending on the degree of aging of the sorbents and how that can decrease adsorption capacity dynamically at the same time that iodine adsorption occurs.

- The decontamination factor (DF, which is the ratio of the flowrate of gaseous iodide entering the sorbent bed divided by the flowrate of gaseous iodide exiting the sorbent bed) for diatomic iodine and organic iodides that were tested. DFs generally trend high enough to meet or exceed minimum values expected to be needed to meet regulatory limits for both DOG and VOG streams. These results provide proof-of-concept confirmation that engineered sorbent bed designs have potential to meet 129I air emission regulatory limits. 
These results are preliminary and limited at this time because the full test matrix in the joint ORNL/INL multi-year test plan ("Joint Test Plan for the Evaluation of Iodine Retention for Long-Chain Organic Iodides,” NTRD-MRWFD-2018-000212, ORNL/SPR-2018/781, February 28, 2018) is not yet completed. In particular, more challenging and difficult-to-perform tests with lower concentrations of gaseous iodides, longer-chain iodides such as iodo-dodecane, and a more complete matrix of tests with varying NOx and moisture levels, have not yet been done. Results and conclusions may need to be updated upon completion of those tests. (J. Law)

[ORNL] The maximum capacity for inorganic iodine on NaZ (silver-free sorbent) was determined using thin-bed testing. This was compared to the maximum capacity for inorganic iodine on AgZ. Both adsorption curves are shown in Figure 1. This data was collected at $150 \mathrm{C}$ with a superficial gas velocity of $10 \mathrm{~m} / \mathrm{min}$. The iodine concentration was $50 \mathrm{ppm}$ and the water dew point was $-70^{\circ} \mathrm{C}$. $\mathrm{NO}$ gas cylinders to support this milestone have been received. (B. Jubin)

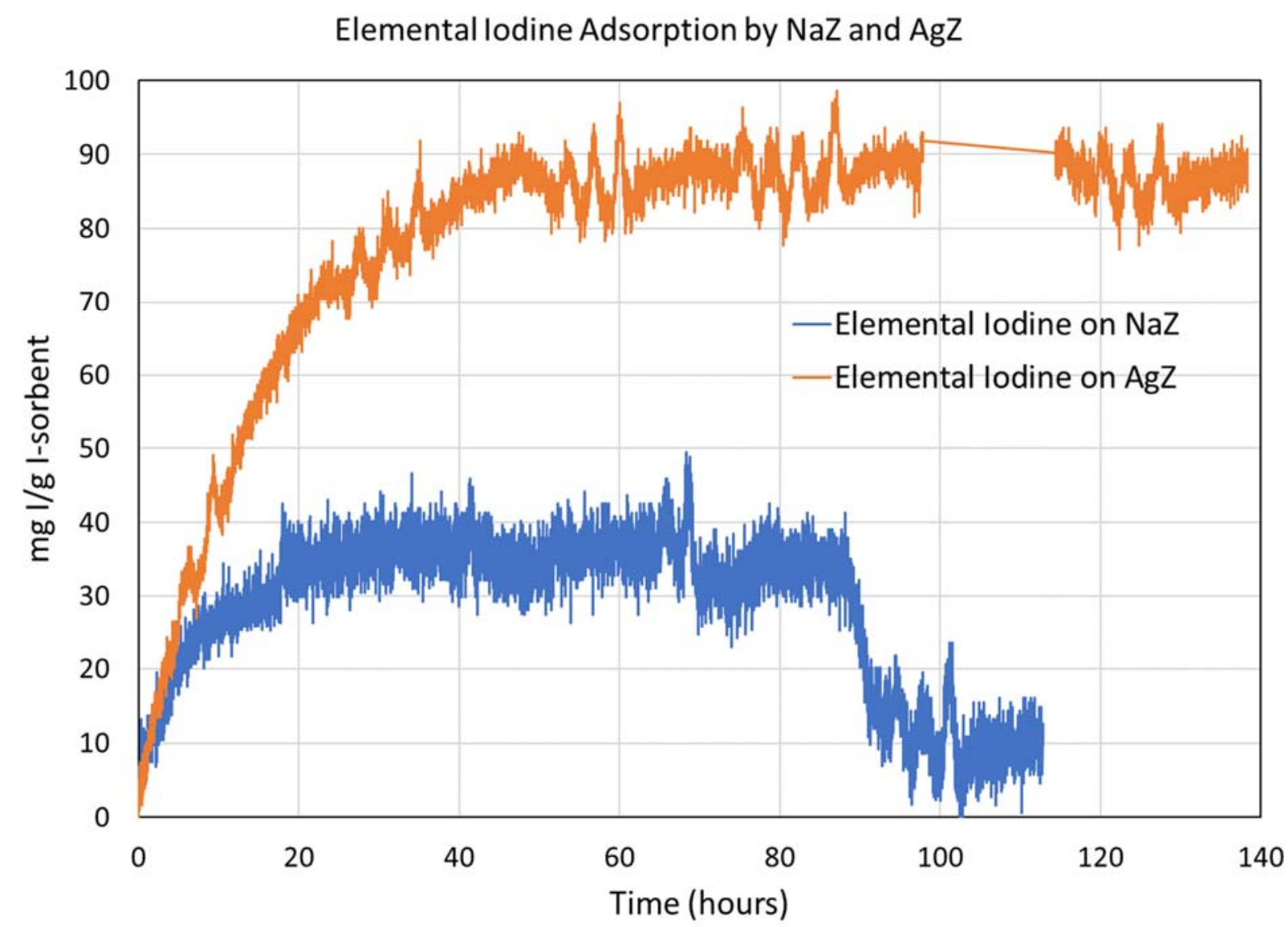

Figure 7. Elemental iodine adsorption by $\mathrm{NaZ}$ and $\mathrm{AgZ}$

[ORNL] The milestone titled, "Evaluate the iodine retention of long-chain organic iodides on both AgZ and AgAerogel over the range of expected concentrations in both the DOG and VOG systems, and issue joint ORNL/INL report," is complete. A summary is included below:

- ORNL and INL have begun the execution of a multi-year joint test plan intended to provide a better understanding of organic iodide adsorption from VOG conditions. In this fiscal year, ORNL has conducted thin bed testing on the adsorption of CH3I and C4H9I by AgZ and has conducted deep bed testing on the adsorption of C4H9I by AgZ. INL has conducted extended duration deep bed testing on the adsorption of C4H9I and CH3I by AgZ and AgAerogel. This 
testing provides data on the adsorption rate as a function of hydrocarbon chain length and concentration. Limited data on the saturation concentration of long-chain iodides on silver-based sorbents has been obtained by both ORNL and INL, and some differences were observed between the two laboratories and across different organic iodine species. Results indicate that once the iodine loading is normalized to Ag content, both $\mathrm{AgZ}$ and $\mathrm{AgAerogel}$ have about the same capacity. DFs over a fixed bed length have been obtained by INL for elemental iodide, CH3I, and C4H9I. DFs generally trend high enough to meet or exceed minimum values expected to be needed to meet regulatory limits. These results provide proof-of-concept confirmation that engineered sorbent bed designs have potential to meet 129I air emission regulatory limits. Both ORNL and INL continue to execute the multi-year joint test plan in close collaboration. Continued success is expected as additional data is obtained and key questions regarding organic iodide by silver-based sorbents are answered. It is expected that completion of the test plan will result in the ability to provide reliable engineering designs for the removal of iodine from VOG streams. (B. Jubin)

\subsection{Flowsheet Demonstrations}

[INL] In September, the final items in the Functional Acceptance Testing of the Material Recovery Pilot Plant (MRPP) were successfully completed. The completion of this testing allowed for the partial turnover of the pilot plant from the subcontractor to INL, which means the pilot plant is ready for initial testing with $\mathrm{HCl}$ gas and with zirconium samples. The Management Self-Assessment of the MRPP was also completed in September with the resolution of the pre-start findings which including finishing the functional testing and completing the work control document Laboratory Instruction (LI)-751 rev 2. LI751 was revised to allow for the use of hazardous gas in the MRPP. (M. Warner)

[ORNL] The hydrochlorination tests under the selected conditions were completed and the results reported in ORNL/SPR-2019/1252, "Perform chlorination scoping tests on aluminum 6061 coupons," issued on 9/19/2019 to complete M3FT-19OR030206018 titled "Perform chlorination scoping tests on aluminum 6061 coupons." The report summarizes the design, construction of the experimental setup, and the results obtained from a series of parametric hydro-chlorination scoping studies using aluminum coupons based on conditions selected in consultation with Idaho National Laboratory. The main scope was to determine the hydro-chlorination kinetics, hydrogen chloride utilization, target temperatures and general behavior. (R. Jubin)

[ANL] ANL has continued to improve the performance of the AMUSE Fortran code, addressing issues as they come up with active use of AMUSE to generate UREX flowsheets. Most of this effort involves comparisons with Excel and Fortran outputs using an analysis tool utilizing the Jupyter Notebook environment to identify and assess any differences. The Jupyter Notebook environment simplifies the mechanism for generating multiple comparisons and provides the user the ability to easily view multiple of these comparisons. The tool can be used to compare simulations of varied flowrates, fractional efficiencies, or effluents.

Over the past month, hydrodynamic testing has continued for both $2-\mathrm{cm}$ and $3-\mathrm{cm}$ contactors with the redesigned rotors. Testing included both zero-point and hold-up testing under varying conditions. The increase in zero-point for the improved rotor design was confirmed to be $67 \%$ higher than the standard configuration, representing a significant capacity boost while keeping the stage footprint constant. Planning has begun for a test of the contactors' stage efficiency and residence time distribution by examining the transient performance of various stages using a surrogate extraction. Concentrations of the output streams will be carried out using UV-vis. (C. Pereira) 
[PNNL] PNNL and INL teams met in Richland, WA for a face-to-face planning session to determine FY2020-FY2021 scope, schedule, budget, and milestone assignments for the melter task. The meeting resulted in a stronger collaboration and more open communication between the teams. (J. Vienna)

For more information on Material Recovery and Waste Forms Development contact Terry Todd (208) 526-3365 


\section{MPACT CAMPAIGN}

\subsection{Management and Integration}

\subsubsection{NTD \& Management Support}

[LANL] NTD, CAM, and Federal Program Manager held a series of teleconferences with FY20 MPACT work package managers to refine FY20 scope based on DOE/NE feedback and guidance. NTD and CAM hosted Kurt Harris (Flibe Energy) at LANL to discuss MSR nuclear material accountancy and control items.

\subsection{Advanced Fuel Cycle Scoping}

\subsubsection{Advanced Process Modeling and Simulation Process Tests}

[PNNL] Completed annual status update and submitted milestone (M3FT-19PN040103011).

\subsubsection{MSR Safeguards}

[ORNL] Findings compiled in a presentation for the ORNL MSR Workshop 2019. Dose estimate calculations complete for a range of samples for input to the milestone report.

\subsubsection{MSR Safeguards Modeling}

[SNL] Continuing to support the MSR safeguards and interface with ORNL. The MSR safeguards model is being refined for work for next year.

\subsubsection{Advanced Fuel Cycle Scoping Review Panel}

[ANL] Completed update and final review of advanced scoping study recommendations report.

[ORNL] Supported the analysis of NMAC issues for safeguards and security for the identified fuel cycle technologies.

\subsection{Safeguards and Security by Design - Echem}

\subsubsection{Microfluidic Sampler}

[ANL] Activities focused on the benchtop testing of the molten salt centrifugal pump and sampling loop droplet generator. Design improvements were implemented based on the results of this benchtop testing. The pump, priming system, and droplet generator all worked well.

\subsubsection{Actinide Sensor}

[INL] Continued sensor tests, characterizing the sensors, and summarizing the overall results in an endof-year report (M3FT-19IN040104025).

\subsubsection{U/TRU Thermocouple Sensor}


[INL] The end-of-year report was submitted on August 31, 2019 (M3FT-19IN040104032). Future work for FY20 was planned based on the FY19 results and discussions with INL colleagues.

\subsubsection{Bubbler for Measuring Density and Depth of Molten Salt}

[INL] Summarized the overall results for FY19 and prepared the end-of-year report.

\subsubsection{OR Voltammetry}

[INL] Summarized the overall results for FY19 and prepared the end-of-year report (M4FT19IN040104051). Some activities were performed on developing/assembling an engineering scale probe for testing in hot fuel examination facility (HFEF) of INL.

\subsubsection{ER Voltammetry}

[ANL] A deliverable report satisfying Milestones M3FT-19AN040104061 and M3FT-19AN040104063 was submitted to the NTD. A version of ANL's multielectrode voltammetry sensor was sent to INL for qualification in the HFEF mock-up area.

\subsection{Modeling Advanced Integration and Milestone 2020:}

\subsubsection{Advanced Integration Methods}

[LANL] Submitted deliverable (M3FT-19LA040105021) and are working on steps for the 2020 milestone.

\subsubsection{Modeling and Simulation for Analysis of Safeguards Performance}

[SNL] The Echem model has been updated for preparation for next year's runs. The model was prepared to distribute to one of the NEUP partners.

\subsection{Exploratory Research / Field Tests}

\subsubsection{Microcalorimetry}

[LANL] The Microcalorimeter User Assessment and Measurement Campaign was successfully completed on a range of spent fuel, uranium, and plutonium materials. The experience demonstrated that the technology readiness level of microcalorimeter gamma spectroscopy has significantly advanced over the past several years. Advances in both instrumentation and data analysis are now making acquisition of high-quality spectra routine and enabling new safeguards capabilities. The measurements described in the M2 milestone (M2FT-19LA040106011) report represent the largest set of ultra-high-resolution, highstatistics microcalorimeter gamma spectra ever recorded. The spectra are now being used to explore signatures of spent fuel, explore uncertainty limits of nondestructive uranium and plutonium isotopic characterization, inform safeguards models, and extract improved nuclear data needed for quantitative gamma spectroscopy. Successful completion of this milestone positions us well for the major FY20 milestone of deploying a microcalorimeter gamma spectrometer to Idaho National Laboratory.

For more information on MPACT contact Mike Browne at (505) 665-5056. 


\section{SYSTEMS ANALYSIS AND INTEGRATION (SA\&I) CAMPAIGN}

\subsection{Campaign Management}

[DOE, ANL, INL, ORNL, LANL, BNL] The SA\&I Campaign Working Group Meeting was held at Argonne, September 17-18, 2019. The accomplishments of FY 2019 and planned activities for FY 2020 were discussed, including the status of the NEUP projects related to the SA\&I campaign. Additionally, a special session was held September 18, 2019 on "Advanced Reactor Concepts and Fuel Recycling," that included Federal Directors/managers, senior leaders from the Material Recovery and Waste Form Development Campaign and Fast Reactor Campaign, and SA\&I Campaign personnel.

[ANL, BNL, INL, LLNL, ORNL, PNNL, SNL] Campaign Lab leads/Work Package Managers completed the Work Packages (WPs) for FY 2020, and the WPs were approved by campaign management.

[INL, ANL] Working with the Federal Manager on several initiatives to support the campaign, including developing a webinar on the TSRA process for HQ personnel.

\subsection{EQUILIBRIUM SYSTEM PERFORMANCE (ESP)}

\subsubsection{Performance of Advanced Nuclear Energy Systems}

[ANL, BNL, INL, ORNL] Completed compilation of the information on newly proposed advanced nuclear energy systems that are currently under development by industries, universities, national laboratories, and foreign entities, and submitted the level 3 milestone report "Technical Insights on Newly Proposed Nuclear Energy Systems" by T. K. Kim, et al. This report is an updated version of the compendium report developed in FY 2018 and includes information on seventeen additional concepts compiled in FY 2019. The set of evaluated nuclear energy systems now includes 73 advanced reactor concepts, 15 nuclear fuel concepts, 4 reprocessing technologies, and 9 national fuel cycle concepts.

[ANL, BNL, INL, ORNL] Presented following paper at Global/Top Fuel 2019 conference:

- Prospective Nuclear Fuel Cycle Characteristics of Advanced Nuclear Energy Systems, by T . K . Kim, T . A . Taiwo, B . W . Dixon, M . Todosow, A . Worrall

\subsubsection{Economic Analysis Capabilities and Assessments}

[INL] Attended a meeting of the Joint IEA/NEA Ad Hoc Expert Group on the Projected Costs of Generating Electricity on September 26 at IEA headquarters in Paris, France. The meeting focused on the consolidated results of questionnaires on costs of electricity for different generation types submitted by member countries and steps necessary going forward to produce the 2020 update of the subject report. This report is updated and issued every 5 years.

[INL] Attended a meeting of the NEA Working Party on Nuclear Economics on September 27 at NEA headquarters in Paris, France. The meeting included presentations on all ongoing work of the expert groups beneath the WP and other activities of interest to the WP, including considerable discussion on several projects. Brent Dixon was elected Vice Chair of the WP.

[PNNL] Attended ANS Global conference and participated as a panelist on Sustainability of Nuclear Energy System in Future Energy Market. Attended DOE NE Systems Analysis \& Integration campaign meeting and gave presentation on FY19 results and FY20 work plan.

[INL] Attended, participated in, and presented at SA\&I campaign meeting at Argonne on September 1718. Drafted plans for consideration on Cost Basis Report enhancements for FY20. 


\subsubsection{Daily Market Studies of Advanced Nuclear Energy Systems}

[ANL, BNL, INL] Presented following paper at Global/Top Fuel 2019 conference:

- Energy Market Simulation Tools to Assess Competitiveness of Nuclear Power Plants, N . Stauff, G . Maronati, P . Talbot, A . Cuadra, R . Ponciroli, T . K . Kim, B . Dixon, T . A . Taiwo

\subsubsection{Enhancements to the Cost Basis Report (CBR) Tool}

[ANL, INL] Presented following paper at Global/Top Fuel 2019 conference:

- $\quad$ Recent Improvements to the Advanced Fuel Cycle Cost Basis Report, F. Ganda, J. K . Hansen, K. A . Williams, E. Hoffman, B . Dixon, T . K . Kim, T . Taiwo.

\subsubsection{Analysis of NES to Augment Information in Fuel Cycle Catalog}

[INL] The modified the summary of ESP analysis for HALEU fuel was sent to ANL with an additional section describing analyses of economic impacts based on the alternative levels of enrichment.

[INL] Participated in Global/Top Fuel 2019 conference held on 09/22-09/26 in Seattle. Presented the paper "Characteristics of TRU fueled SFR core during the partial loading of LEU assemblies."

\subsubsection{Maintain/Update Campaign Analysis Tools}

[ORNL] Some early preparatory work was started on the updated improvements for Cyclus in order to demonstrate a proof in principle. ORNL created a cloud virtual machine via Microsoft Azure, installed Cyclus and its modules, for users to use Cyclus without having a local installation.

[SNL] Most of the data for both fuel cycle options (Chinese and Indian) and for the reactor (AHWR) have been entered and verified and is available on the public Nuclear Fuel Cycle Options Catalog. As soon as the interactive flow diagram and the isotopic data for the Indian fuel cycle are available, these also will be made available on the public Nuclear Fuel Cycle Options Catalog site. A representative from SNL also attended the Systems Analysis and Integration Campaign meeting at ANL on September 17-18, 2019.

\subsubsection{Campaign Special Sessions at International Topical Conference}

[ANL, INL, PNNL] Hosted a special panel session entitled "Sustainable Strategies for Nuclear Energy Systems under Future Energy Market Environments" during the Global/Top Fuel 2019 conference on September 24, 2019. In this session, experts on nuclear fuel cycle cost, daily energy market outlook, and advanced reactors, from the SA\&I campaign discussed the sustainable strategies for nuclear energy systems in future energy markets. The session was well attended and reflected positively on our DOE NE program.

[ANL, BNL, INL, ORNL] Hosted five technical sessions in the Global/Top Fuel 2019 conference, and the sessions were chaired by early career experts from the SA\&I campaign;

- $\quad$ Fuel Cycles Scenario Analysis - I, chaired by N. Stauff (ANL)

- $\quad$ Fuel Cycles Scenario Analysis - II, chaired by B. Feng (ANL)

- Fuel Cycle Modeling and Simulation - I, chaired by E. Davison (ORNL)

- Fuel Cycle Modeling and Simulation - II, chaired by E. Hoffman (ANL)

- $\quad$ Trends in Nuclear Energy Fuel Cycles, chaired by R. Hays (INL)

[INL] Participated in the Global/Top Fuel 2019 panel session "Sustainable Strategies for Nuclear Energy Systems under Future Energy Market Environments" as a panelist. 


\subsubsection{Quick Turn-Around Studies}

[LLNL]. Provided technical review of the ANL deliverable "Report on Newly Proposed Nuclear Energy systems", ANL/NSE-19/26. Provided comments on a draft book chapter on fuel cycle alternatives.

\subsubsection{Beyond Levelized Cost of Electricity}

[INL] Provided an oral report "DOE-Wide Beyond Levelized Cost of Electricity Study" at the campaign meeting on NE activities associated with this project in FY-19, completing a Level 3 milestone to "Report on Campaign Participation in Beyond LCOE Activity". The document "Office of Nuclear Energy Contributions to Beyond LCOE Phase 1" containing the presentation slides was prepared and entered into the PICS-NE system documenting completion.

[INL] This project is currently paused at HQ request while EE, FE, and NE work out differences on project objectives. As part of the management team on the lab side, working behind the scenes to help identify differences and how they could be resolved.

\subsection{DEVELOPMENT, DEPLOYMENT AND IMPLEMENTATION ISSUES (DDII)}

\subsubsection{Technology Development Roadmap for a Continuous Recycle System Using Fast Reactors}

[INL, ANL, BNL, LLNL] Presented following paper at Global/Top Fuel 2019 conference: Using a Technology and Systems Readiness Assessment to Roadmap a Nuclear Energy R\&D Program, B . W . Dixon, W . G . Halsey, T . K . Kim, G . Matthern, N . R. Soelberg, M. Todosow. The paper provided an overview of the TSRA process with focus on recent accomplishments in proof-testing development of Technology Maturation Plans and rolling them up into Technology Roadmaps.

[INL] Participated in the annual working group meeting for the campaign on Sept. 17-18 at ANL, including making presentations on TSRA and Beyond LCOE.

\subsubsection{Transition Analysis Studies}

[ANL, ORNL] Presented following papers at Global/Top Fuel 2019 conference:

- Technology Characteristics of Transitions to Solid-Fueled and Molten-Salt Fast Reactor Fleets, E . Hoffman, B . Feng, B . Betzler, E . Davidson, A . Worrall

- Fast Reactor Design for Using Low-Enriched Uranium Startup and Transition, E . Hoffman, T . Fei

[INL] Chaired a meeting of the NEA/OECD Expert Group on Advanced Fuel Cycle Scenarios on September 11-12 at NEA headquarters in Paris, France. The meeting focused on status and actions to complete the report on the current project on TRU management and work needed prior to the next meeting to start the next project on feasibility of continuous recycling with water-cooled reactors.

[ORNL] Two papers were presented at the GLOBAL conference. The first on the fuel cycle performance of different fast spectrum molten salt reactors within the context of the Evaluation \& Screening Study. The presentation was well-attended, and the work stressed the consistency of findings with the E\&S Study findings and highlighted potential impacts on transition times due to initial fissile material inventory and out-of-core salt volumes. The second was on the Functionality Isolation Test for Fuel Cycle Code ORION - MOX Fabrication. 
[ANL] Participated, via Webex video-teleconference, in the meeting of the OECD-NEA Advanced Fuel Cycle Scenarios Expert Group involving international experts in fuel cycle systems modeling. The twoday meeting involved discussing the final report writing and results for the TRU Management benchmark and beginning a new activity on investigating the feasibility of continuous recycle in water-cooled reactors. The ANL participant shared a presentation based on his previous work on this issue in 2014 that was supported by the SA\&I Campaign in the hopes of encouraging participation and demonstrating US leadership on this topic.

\subsubsection{Regional and Global Impacts}

[PNNL] Attended OECD NEA expert group meeting in Paris on Advanced Reactors for Future Energy Markets (ARFEM) and contributed to the goal of publishing NEA technical report.

\subsubsection{Adaptation of OR-SAGE for NES Analysis}

[ORNL] The level-3 milestone report "Adaptation of OR-SAGE Siting Analyses for Advanced Nuclear Energy Systems", M3FT-19OR120103051, was completed. This report provides a summary of the further development and application of the dynamic visualization database tool, OR-SAGE, to advanced nuclear energy systems, specifically the fuel cycle facilities. The OR-SAGE tool has been further developed in FY19 under the Systems Analysis and Integration (SA\&I) Campaign to enable additional functionality including application to fuel cycle facilities, advanced fuel cycle deployment scenarios, and transportation considerations. The expansion tool, Oak Ridge Advanced Fuel Cycle Logistics Environment (ORACLE), will ultimately allow stakeholders to perform interactive parameter and sensitivity studies for the evaluation of fuel cycle facility deployment and optimization. The strength of the ORACLE tool is that numerous alternative scenarios can be quickly generated to provide additional insight into the advanced reactor fuel cycle, its deployment, logistics, and transport. The screening is rapid as well as readily visualized, hence making it easier to engage decision makers and other non-expert stakeholders and could readily be used for any early or preliminary site screening assessments. In addition to the summary of the development of ORACLE, the report also provides an example application of a siting assessment of SMRs on existing U.S. fuel cycle facility sites and several DOE federal sites. The assessment is not intended to draw any conclusions on the suitability or viability of any specific site, or should it be seen as a replacement for a detailed siting or environmental assessment. But the tool and work here does highlight how GIS technology as well as site choices are key in the future utilization and expansion of nuclear for given markets and applications, as well as underlines the value of the siting tools.

For more information on Systems Analysis and Integration contact Temitope Taiwo (630) 252-1387. 


\section{JOINT FUEL CYCLE STUDY ACTIVITIES}

The first $4 \mathrm{~kg}$-scale test with irradiated LWR fuel in the oxide reduction system was completed. Initial data indicate a $>90 \%$ conversion of oxide fuel to metal following oxide reduction and salt separation at this scale.

Fuel from an additional 13 irradiated LWR fuel elements was separated from cladding using the decladding equipment. This brings the total to 18 declad irradiated LWR fuel elements and provides feedstock material for three tests at $4 \mathrm{~kg}$-scale.

An electrorefining test with depleted uranium material was completed as a system shake-down. This test used material previously reduced in the oxide reduction system at $4 \mathrm{~kg}$-scale to optimize test parameters for LWR fuel.

For more information on Joint Fuel Cycle Studies Activities contact Ken Marsden (208) 533-7864. 


\section{AFCI-HQ PROGRAM SUPPORT}

Site: University Research Alliance at West Texas A\&M University in Canyon TX, and the following universities: Ohio State University, University of Tennessee at Knoxville, Georgia Institute of Technology, University of Idaho, Colorado School of Mines, University of South Carolina, Florida State University, Northwestern University, Clemson University, North Carolina State University, University of Utah, University of Chicago, Columbia University, University of Toledo, and other universities.

Universities engaged in Nuclear Technology research via URA programs since 2001:

Boise State University

Boston College

Clemson University

Colorado School of Mines

Columbia University

Georgia Institute of Technology

Georgetown University

Idaho State University

Florida International University

Florida State University

Kansas State University

Massachusetts Institute of Technology

Missouri University of Science and

Technology

North Carolina State University

Northern Illinois University

Northwestern University

Ohio State University

Oregon State University

Pennsylvania State University

Purdue University

Rensselaer Polytechnic Institute

Rutgers University

Texas A\&M University

University of Arkansas
University of California at Berkeley

University of California at Santa Barbara

University of California at Davis

University of Chicago

University of Cincinnati

University of Florida

University of Idaho

University of Illinois at Urbana-Champaign

University of Michigan

University of Missouri

University of Nevada at Las Vegas

University of New Mexico

University of North Texas

University of Notre Dame

University of Ohio

University of South Carolina

University of Tennessee at Knoxville

University of Texas at Austin

University of Toledo

University of Utah

University of Virginia

University of Wisconsin

Vanderbilt University

Virginia Commonwealth University

Washington State University 


\subsection{Innovations in Nuclear Technology R\&D Awards}

\subsubsection{University Programs}

\subsubsection{Summary Report}

University Research Alliance provided information to the First Place Innovations Awards winners and worked with the award winners and the American Nuclear Society on the Innovations in Nuclear

Technology R\&D Awards special session and celebratory dinner to be held at the ANS Winter Meeting in November.

University Research Alliance ordered desktop awards for the 2019 award winning students.

University Research Alliance continued to update the Innovations Awards announcement distribution list in anticipation of the 2020 Innovations Awards.

For more information on the University Research Alliance contact Cathy Dixon (806) 651-3401. 